OPEN ACCESS

Edited by:

Alexander C. Jackson, University of Connecticut,

United States

Reviewed by:

Eric E. Turner,

Seattle Children's Hospital,

United States

Christopher S. Leonard,

New York Medical College,

United States

*Correspondence:

Francisco E. Olucha-Bordonau folucha@uji.es

Received: 04 December 2020 Accepted: 26 February 2021

Published: 18 March 2021

Citation:

Gil-Miravet I, Mañas-Ojeda A, Ros-Bernal F, Castillo-Gómez E, Albert-Gascó H, Gundlach AL and Olucha-Bordonau FE (2021) Involvement of the Nucleus Incertus and Relaxin-3/RXFP3

Signaling System in Explicit and Implicit Memory.

Front. Neuroanat. 15:637922. doi: 10.3389/fnana.2021.637922

\section{Involvement of the Nucleus Incertus and Relaxin-3/RXFP3 Signaling System in Explicit and Implicit Memory}

\author{
Isis Gil-Miravet ${ }^{1}$, Aroa Mañas-Ojeda ${ }^{1}$, Francisco Ros-Bernal ${ }^{1}$, Esther Castillo-Gómez ${ }^{1,2}$, \\ Hector Albert-Gascó ${ }^{3}$, Andrew L. Gundlach ${ }^{4}$ and Francisco E. Olucha-Bordonau 1,2* \\ ${ }^{1}$ Unitat Predepartamental de Medicina, Facultat de Ciències de la Salut, Universitat Jaume I, Castelló de la Plana, Spain, \\ ${ }^{2}$ Centro de Investigación Biomédica en Red de Salud Mental, CIBERSAM, Madrid, Spain, ${ }^{3}$ Department of Clinical \\ Neurosciences, UK Dementia Research Institute, University of Cambridge, Cambridge, United Kingdom, ${ }^{4}$ The Florey Institute \\ for Neuroscience and Mental Health, The University of Melbourne, Parkville, VIC, Australia
}

Telencephalic cognitive and emotional circuits/functions are strongly modulated by subcortical inputs. The main focus of past research on the nature of this modulation has been on the widespread monoamine projections to the telencephalon. However, the nucleus incertus (NI) of the pontine tegmentum provides a strong GABAergic and peptidergic innervation of the hippocampus, basal forebrain, amygdala, prefrontal cortex, and related regions; and represents a parallel source of ascending modulation of cognitive and emotional domains. NI GABAergic neurons express multiple peptides, including neuromedin-B, cholecystokinin, and relaxin-3, and receptors for stress and arousal transmitters, including corticotrophin-releasing factor and orexins/hypocretins. A functional relationship exists between NI neurons and their associated peptides, relaxin-3 and neuromedin-B, and hippocampal theta rhythm, which in turn, has a key role in the acquisition and extinction of declarative and emotional memories. Furthermore, RXFP3, the cognate receptor for relaxin-3, is a $\mathrm{G}_{\mathrm{i} / \mathrm{o}}$ protein-coupled receptor, and its activation inhibits the cellular accumulation of CAMP and induces phosphorylation of ERK, processes associated with memory formation in the hippocampus and amygdala. Therefore, this review summarizes the role of $\mathrm{NI}$ transmitter systems in relaying stressand arousal-related signals to the higher neural circuits and processes associated with memory formation and retrieval.

Keywords: neuropeptide, RXFP3, GABA, brainstem, amygdala, hippocampus

\section{INTRODUCTION}

Forebrain function is driven by subcortical ascending connections resulting in arousal activation allowing cognitive and emotional processes. The Ascending Reticular Activating Systems (ARAS) concept was postulated on the basis of the classical work of Moruzzi and Magoun (1949). In this pioneering research, upper brainstem stimulation resulted in the shift from high voltage synchronized sleep EEG to low voltage desynchronized EEG of wakefulness. Ascending pathways 
from the pontine-mesencephalic reticular projections to the thalamus were initially proposed as the central core of the ARAS (Steriade and Glenn, 1982). However, the complexity of the ascending projections arising from the ponto-mesencephalic reticular formation and the contribution of non-reticular brainstem structures lead to the consideration of the relevance of the basal forebrain as a key relay for these ascending systems in arousal performance (Parvizi and Damasio, 2001). In this context, the basal forebrain, including the medial septum (MS), was seen as a key element in driving hippocampal theta rhythm, a synchronizing hippocampal wave associated with movement (Vanderwolf, 1969).

The MS plays a central role in driving hippocampal theta rhythm as the endpoint of ascending projections arising from the mammillary bodies, median raphe, and (reticularis pontis oralis RPO; Bland et al., 1994; Vertes and Kocsis, 1997). All components of this ascending system are targeted by the pontine nucleus incertus (NI; Goto et al., 2001; Olucha-Bordonau et al., 2003), which led to the proposal that the NI was also a key element in driving hippocampal theta, and thus was a component of the ARAS (Olucha-Bordonau et al., 2003). At the same time, it was discovered that the rat NI contained neurons producing the neuropeptide, relaxin-3 (Burazin et al., 2002; Tanaka et al., 2005; Ma et al., 2007), which interacted with multiple stress and arousal transmitter systems (Ma et al., 2013, 2017b; Blasiak et al., 2015). Thus, the NI is a complex structure composed predominantly of GABAergic neurons in the rat (Ford et al., 1995; OluchaBordonau et al., 2003; Ma et al., 2007) and mouse (Smith et al., 2010) brain, and populations of NI GABAergic neurons co-express neuromedin-B (NMB; Lu et al., 2020; Nasirova et al., 2020), cholecystokinin (Kubota et al., 1983; Olucha-Bordonau et al., 2003) and/or neurotensin (Jennes et al., 1982), as well as relaxin-3, in both species. This neurochemical heterogeneity is also reflected physiologically, as a majority of relaxin-3 neurons in the rat NI increase their firing rate in response to CRF, while non-relaxin-3 neurons can increase or decrease their firing rate (Ma et al., 2013). Moreover, most relaxin-3 NI neurons preferentially fire at the initial ascending phase of the hippocampal theta rhythm, while non-relaxin-3 neurons do not display any relationship with hippocampal theta rhythm ( $\mathrm{Ma}$ et al., 2013).

Concerning arousal modulation during wake/sleep function, it was widely proposed that ARAS promoting centers in the brainstem act via slow mechanisms driven by monoaminergic, cholinergic, and peptidergic systems (Jones and Webster, 1988; Burlet et al., 2002; Berridge and Waterhouse, 2003; Xu et al., 2004). This view was challenged by several experiments in which multiple ablations of these systems produced little effect on wake/sleep proportions. This resulted in a focus on the possibility that fast glutamatergic/GABAergic projections drive a more accurate control on arousal centers (Saper and Fuller, 2017). In this respect, the NI provides an ascending projection that contains the fast transmitter, GABA (Ford et al., 1995; OluchaBordonau et al., 2003), and several slower-acting peptidergic modulators (Ma et al., 2007; Ma and Gundlach, 2015, 2017b).

Notably, NI neurons project to most components of the ARAS, including those responsible for the subcortical triggering of hippocampal theta rhythm (Vertes and Kocsis, 1997; Tanaka et al., 2005; Ma et al., 2007; Smith et al., 2010), and thus are well-positioned to play a role in modulating memory acquisition and retrieval. In line with the widespread projections of the NI system, several lines of research have indicated its involvement in a range of functions, including stress (Banerjee et al., 2010; Ryan et al., 2013a), food intake (Ganella et al., 2013a; Lenglos et al., 2013; Calvez et al., 2017), alcohol addiction (Ryan et al., 2013b, 2014), arousal (Ryan et al., 2011; Ma et al., 2017a), and memory generation and retrieval (Nategh et al., 2015; Haidar et al., 2017, 2019; Szönyi et al., 2019; Lu et al., 2020).

Therefore, previous reviews of the neurobiology of the NI and its relaxin-3 signaling system have focused on a likely role in stress and arousal (Ryan et al., 2011; Ma and Gundlach, 2015), feeding behavior (Ganella et al., 2013b), and a possible involvement in mental illnesses (Smith et al., 2014; Kumar et al., 2017) with a summary of associated relaxin-3 signaling via RXFP3 (Ma et al., 2017b; Olucha-Bordonau et al., 2018). In this review, our goal was to discuss the basis on which these different functions are linked to memory processes and how relaxin-3/RXFP3 signaling supports such functions. For example, memory is relevant when searching for places containing food resources. However, while there is a perception that brainstem nuclei, including the NI, provide general widespread modulation of telencephalic circuits/functions, this idea has been challenged by the recent demonstration of a likely role of NI GABAergic neurons in selecting relevant memory information (Szönyi et al., 2019). Therefore, here we review the main findings related to the role of the NI and the relaxin-3/RXFP3 signaling system in explicit and implicit memories, and discuss current gaps in our knowledge, along with possible developments and future directions that will help to better determine the precise role of this system in learning processes.

\section{NUCLEUS INCERTUS/RELAXIN-3 INNERVATION OF MEMORY-RELATED CENTERS}

Relaxin-3 was the last member of the relaxin family to be discovered (Bathgate et al., 2002; Burazin et al., 2002; Gundlach et al., 2013), but represents the ancestral form of the other relaxin family peptides. Similar to insulin peptides, mature relaxin-3 is composed of an A- and B-chain linked by two disulfide bonds. The B-chain peptide contains the characteristic "RXXXRXX(I/V)" sequence, which has been maintained in all vertebrates (Wilkinson and Bathgate, 2007). Two years after the peptide discovery, the $G_{i / o}$ protein-coupled receptor, GPCR135, was identified as the cognate receptor for relaxin-3 and was renamed as the relaxin family peptide 3 receptor (RXFP3). Relaxin-3 mRNA expression was found to be most abundant in the brain (Burazin et al., 2002), with some expression in other organs such as the lungs, liver, spleen, thymus, and gonads (Bathgate et al., 2002).

The relaxin-3 expression is predominantly located in neurons of the NI of the pontine tegmentum in rats, mice, and macaque (Burazin et al., 2002; Ma et al., 2009b; Smith et al., 2010). 
Also, studies of peptide mRNA and immunoreactivity in rat and mouse revealed three additional relaxin-3-positive neural groups located in the lateral part of the substantia nigra, the ventrolateral part of the periaqueductal gray (PAG), and the pontine raphe nucleus (Tanaka et al., 2005; Ma et al., 2007; Smith et al., 2010). Notably, while in the rat brain, most ( $50 \%)$ relaxin-3 neurons are concentrated in the NI over a rostrocaudal extension of $750 \mu \mathrm{m}$; in the PAG, these neurons appear dispersed along a rostrocaudal column extending approximately 3,000 $\mu \mathrm{m}$. This column is ventrolaterally located to the aqueduct, but in 20-40 $\mu \mathrm{m}$ coronal sections, only 3-4 relaxin-3 positive neurons appear in each hemisphere, but the total number of relaxin-3 neurons represents $50 \%$ of the number in the NI. Thus, these neurons should be considered as a relevant source of relaxin-3 in the brain (Blasiak et al., 2013), particularly as part of the brainstem intrinsic circuitry (Nasirova et al., 2020). Furthermore, anatomical data suggest that the pontine raphe nucleus is a rostral extension of the NI (Nasirova et al., 2020). While it is often considered a serotoninergic nucleus (Hale and Lowry, 2011), the number of neurons positive for serotonin (5-HT) in the pontine raphe nucleus is lower than the number of relaxin-3 positive neurons (Tanaka et al., 2005). In contrast, the number of relaxin-3 neurons in the lateral part of the substantia nigra is very low, even in colchicine-treated rats, with only 2-3 neurons observed in consecutive $40 \mu \mathrm{m}$ sections (Tanaka et al., 2005; Smith et al., 2010; Blasiak et al., 2013). Thus, apart from an earlier study of the PAG to intergeniculate nucleus relaxin-3 pathway and its likely role in circadian rhythms (Blasiak et al., 2013), the focus of research on relaxin-3 neurobiology has largely centered on NI relaxin-3 neurons.

NI has widespread connections to telencephalic centers that play a major role in the acquisition, storage, and retrieval of explicit (hippocampal-dependent) and implicit (amygdaladependent) memories. NI connections include subcortical centers that modulate hippocampal and amygdala function, including the MS, supramammillary nuclei, and both the median and dorsal raphe nuclei in the rat (Goto et al., 2001; OluchaBordonau et al., 2003), mouse (Smith et al., 2010; Szönyi et al., 2019; Lu et al., 2020; Nasirova et al., 2020) and non-human primate (Ma et al., 2009b).

As mentioned, and discussed in detail below, the NI contains heterogeneous populations of GABAergic neurons containing different neuropeptides, including relaxin-3, NMB, or cholecystokinin. Generally, the precise role of these peptides in NI function remains to be investigated, although multiple studies have focused on the involvement of relaxin-3 in several modalities.

\section{RELAXIN-3/RXFP3 SIGNALING AND INTERFERENCE WITH PLASTIC MEMORY PROCESSES}

While research over the last two decades has implicated the relaxin-3/RXFP3 system in a wide variety of functions, including modulation of stress, anxiety, foraging, and addictive and social behaviors (see Ma et al., 2017b; Olucha-Bordonau et al., 2018), for this review we examined the evidence for a specific role of NI transmitter systems, particularly relaxin-3/RXFP3, in relaying stress- and arousal-related signaling to higher neural centers associated with memory formation and retrieval.

ERK phosphorylation and cAMP synthesis/degradation are two processes directly related to plastic memory changes occurring in the hippocampus and the amygdala. The activation of protein kinase A (PKA) by cAMP has been associated with long-term potentiation (LTP) in the hippocampus (Frey et al., 1993; Huang et al., 1994; Abel et al., 1997) and is required for long-term spatial memory in the Morris water maze (MWM; Abel et al., 1997). Similarly, the cAMP/PKA signaling pathway is required and sufficient to induce LTP in the thalamoamygdala and cortico-amygdala systems (Fourcaudot et al., 2008). Similarly, PKA is required for plastic changes associated with emotional memories in the amygdala associated with fear conditioning (Goosens et al., 2000; Moita et al., 2002). Thus, inhibition of cAMP levels by RXFP3 activation may impair the formation of memories under these or similar experimental and physiological conditions.

In the adult brain, ERK phosphorylation is also a process associated with memory generation, depending on the specific circuits involved. In the hippocampus, ERK phosphorylation has been found to mediate plastic changes induced by LTP in hippocampal slices (Selcher et al., 2001). Similarly, the formation of the hippocampal cognitive map is associated with ERK phosphorylation in specific hippocampal regions (Blum et al., 1999; Selcher et al., 1999). ERK phosphorylation also mediates LTP-related plasticity induced by thalamo-amygdala stimulation of the fear circuit (Apergis-Schoute et al., 2005). This process is also associated with fear memory acquisition and consolidation (Schafe et al., 2000). ERK2 mutant mice have been characterized as displaying impairment in social recognition and other social behavior problems (Satoh et al., 2011).

Relaxin-3 binds to RXFP3 with high affinity $\left(\mathrm{K}_{\mathrm{d}}\right.$ $300 \mathrm{pM}$ ) and in vitro studies in Chinese hamster ovary (CHO)-K1 cells overexpressing RXFP3 revealed that the addition of recombinant relaxin-3 to the media resulted in inhibition of cAMP accumulation (Liu et al., 2003). In similar experimental models, it was demonstrated that RXFP3 activation resulted in the activation of the MAP-ERK pathway in a PKC-dependent manner (Van der Westhuizen et al., 2005, 2007; Figure 1). In vivo, intracerebroventricular (icv) infusions of an RXFP3 agonist increased ERK phosphorylation in the septum (Albert-Gascó et al., 2017) and amygdala (Albert-Gasco et al., 2019) reaching a peak at $20 \mathrm{~min}$ and returning to baseline (control) values by $90 \mathrm{~min}$. However, this pERK activation was largely produced in RXFP3 mRNA negative neurons in these regions, suggesting this in vivo ERK activation was an indirect effect (Albert-Gasco et al., 2019).

Under normal conditions, pERK activation is known to be produced in the medial amygdala (MeA) during a social interaction test and social recognition memory without relaxin3/RXFP3 modulation. This is a likely reason why $20 \mathrm{~min}$ after RXFP3 agonist infusion, the MeA still displays a considerable amount of pERK positive neurons, which do not express RXFP3. These pERK-positive neurons are likely to be a result of social 


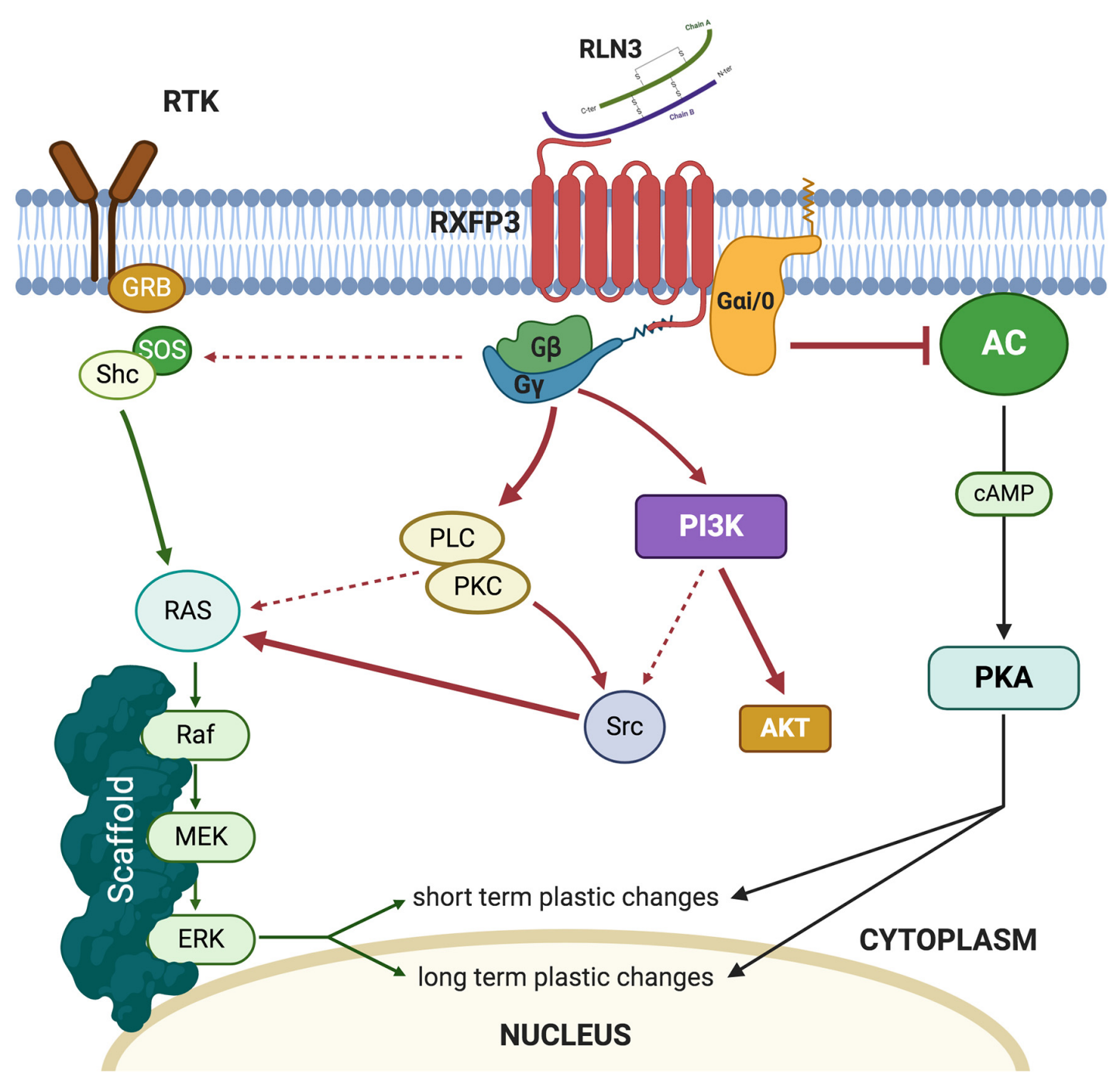

FIGURE 1 | Summary of the intracellular pathways triggered by relaxin-3 (RLN3) activation of RXFP3.

behavior rather than an indirect effect of relaxin-3/RXFP3 system activation. This argument is supported by the fact that activating RXFP3 during this behavioral paradigm significantly increased the number of RXFP3-expressing neurons which contained pERK compared to controls, suggesting a direct effect on these neurons. However, all studies where RXFP3 agonists increased pERK were quantified after assessing retrieval of memories (Albert-Gascó et al., 2017; Albert-Gasco et al., 2019). So, it is possible, given the transient nature of MAPK activation, that these approaches are likely to have missed the complete direct increase of pERK in RXFP3-expressing neurons due to RXPF3 agonist activation. These results support the hypothesis that experimental timing is crucial to determine the role and adequately delimit the downstream pathways which mediate relaxin-3/RXFP3 induced neuronal plasticity. Another relevant aspect that remains to be assessed is how RXFP3 agonist activation modulates neuronal firing patterns within its different targeted areas. Electrophysiological studies in brain slices which focused on the hypothalamus and the bed nucleus of the stria terminalis demonstrated a reversible inhibition of neuronal firing (Kania et al., 2017, 2020; Ch'ng et al., 2019).

Thus, a balance between inhibition of cellular cAMP levels and ERK phosphorylation in particular neurons of the amygdala and hippocampus may result in particular aspects of experienced events being filtered out and others being enhanced in a particular environmental or social context. Currently, there is a lack of data on the effects of RXFP3 activation on the cAMP/PKA system or the electrophysiological consequences of RXFP3 activation in the amygdala and hippocampus, and more research is needed to decipher these key aspects of this dual cell signaling system and the nature of its complex regulation by RXFP3.

Furthermore, little is known about the effect(s) of the presumed co-release of GABA and relaxin-3. EM images of NI 
terminals are reported to contain the oval vesicles of GABAergic terminals and contain dense-core vesicles (DCV) associated with peptide storage (Tanaka et al., 2005; Ma et al., 2009a; Olucha-Bordonau et al., 2012). NI neurons including those that are relaxin-3-positive are GABAergic, and GABA and peptides may act in co-operation or in opposition at postsynaptic targets, depending upon the nature of the peptide and its receptor(s). Unfortunately, little is known about the specific dynamic modulation of relaxin-3 release from DCV at nerve terminals or the precise type of stimulation that leads to relaxin-3 release. More generally, it is thought that DCV are released after high-frequency stimulation (Hartmann et al., 2001), and if this is the case for GABA/relaxin-3-positive neurons, train stimulation of the NI would lead to the release of relaxin-3 at nerve terminals. In neuropeptide systems, the neuropeptide tends to be co-released with other neurotransmitters, being GABA in the case of relaxin-3 neurons. In most cases, transmitter and peptide release do not occur as separate events but can have different behavioral outcomes (Hartmann et al., 2001), and therefore it is likely that the NI/relaxin-3 system modulates GABAergic signaling, synergizing with its effects, given that RXFP3 is a $\mathrm{G}_{\mathrm{i} / \mathrm{o}}$-protein-coupled receptor. However, more experiments are needed to fully understand the dynamics of the NI/relaxin-3/ GABA system.

\section{NUCLEUS INCERTUS AND HIPPOCAMPAL THETA RHYTHM}

Early seminal studies demonstrated that when a rat enters and explores a new environment, a cognitive map is formed in the hippocampus, whereby groups of cells fire specifically when the rat passes along a particular place field (O'Keefe and Dostrovsky, 1971). Directly related to the emergence of place cells, locomotion during the active exploration of the context generates a synchronic wave of 4-12 Hz called theta rhythm (Vanderwolf, 1969; Buzsáki et al., 1983). A particular feature of the link between the cognitive map and hippocampal theta rhythm is the theta precession. When a rat approaches a particular place field, place neurons fire regularly following theta rhythmicity, but the spikes move progressively to an anterior phase of theta as the rat passes through the place field (O'Keefe and Recce, 1993). Thus, while an animal moves along a path, a set of place cells fire sequentially according to the phase of the local field potential, which is known as theta sequences (O'Keefe and Recce, 1993; Drieu and Zugaro, 2019). In contrast, theta precession and theta sequences have been observed in circumstances where locomotion does not necessarily involve a change in space, like wheel-running, treadmill-running, or virtual reality (Pastalkova et al., 2008; Royer et al., 2012; Chen et al., 2013). All these data suggest that theta precession and theta sequences are not only linked to space and context, but all components of episodic memory (Jaramillo and Kempter, 2017). Along with these processes, a cognitive map is formed, stored, and eventually retrieved in the hippocampus containing an egocentric and an allocentric component. The egocentric component is taken from reference to the self-movement, while the allocentric component is taken from external references (Burgess, 2006).

Theta can be triggered via different mechanisms. First, oscillation at theta frequencies can be elicited from membrane resonance provided by intrinsic properties of various voltagedependent channels (Evstratova et al., 2011). Second, theta can arise from intrinsic hippocampal connections including rhythmic inputs from the entorhinal cortex targeting the dentate gyrus, CA3 or CA1 fields (Alonso and García-Austt, 1987a,b), activation of CA1 cells from CA3 inputs (Kamondi et al., 1998), and interneuronal networks (Goutagny et al., 2009). Finally, theta can be elicited from ascending subcortical projections arising mainly from the MS and the supramammillary nucleus, the median raphe, and the NI (Kocsis and Vertes, 1997; Vertes and Kocsis, 1997; Vertes et al., 1999; Nuñez et al., 2006; Tsanov, 2015; Ruan et al., 2017).

The role of the NI in theta rhythm generation was first hypothesized based on its anatomical connectivity (OluchaBordonau et al., 2003). Ascending connections arising from the NI target sequentially the median and dorsal raphe, supramammillary nucleus, MS, entorhinal cortex, and hippocampus, and each of these nodes provides additional ascending connections to the upstream components of the system, converging in the hippocampus (Olucha-Bordonau et al., 2003). In urethane anesthetized rats, electrical stimulation of the NI elicited an increase in the theta band of the local field potential and at the same time a decrease in the delta band. Moreover, lesions of the NI eliminated the theta rhythm induced by sensory stimulation or electrical stimulation of the nucleus reticularis pontis oralis (RPO; Nuñez et al., 2006). Similarly, infusion of R3/I5, a selective RXFP3 agonist (Liu et al., 2005), into the MS elicited hippocampal theta rhythm in urethane anesthetized rats; and this increase was prevented by a prior infusion of $\mathrm{R} 3(\mathrm{~B} \Delta 23-27) \mathrm{R} / \mathrm{I} 5$, a selective RXFP3 antagonist (Kuei et al., 2007). Furthermore, infusion of the RXFP3 antagonist into the MS disrupted the increase in hippocampal theta produced by RPO stimulation (Ma et al., 2009a; Figure 2).

Indeed, the relationship between theta oscillations in the hippocampus and the NI has been consistently observed using acute recordings in urethane anesthetized rats. Strong coherence in the local field potential between the hippocampus and the NI was observed following sensory or RPO stimulation (Cervera-Ferri et al., 2011). Furthermore, it was observed that a specific type of electrophysiologically characterized neuron in the NI increased firing after sensory stimulation-induced hippocampal theta and was phase-locked with hippocampal theta (Martínez-Bellver et al., 2015). Chemically characterized neurons also displayed a differential firing in relation to the hippocampal theta. While relaxin-3 negative neurons of the NI did not fire in a particular way in relation to theta, relaxin-3 positive neurons fire mainly in the ascending phase of hippocampal theta ( $\mathrm{Ma}$ et al., 2013). Indeed, a causal relationship was identified between the theta phases of the hippocampus and the NI when Granger causality analysis was applied, in which NI activity induced a reset of hippocampal theta (Martínez-Bellver et al., 2017). As an anatomical substrate 

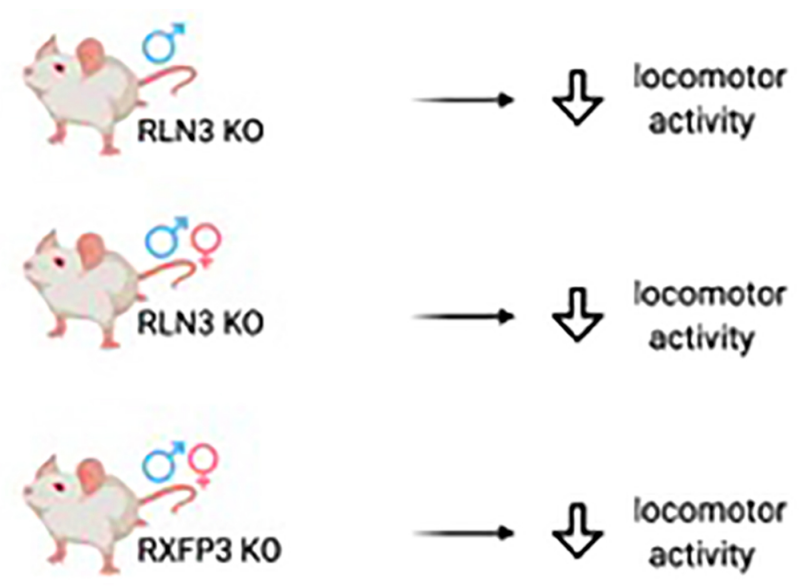

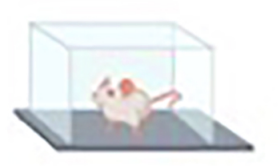

$\longrightarrow$ (Smith et al. 2009)
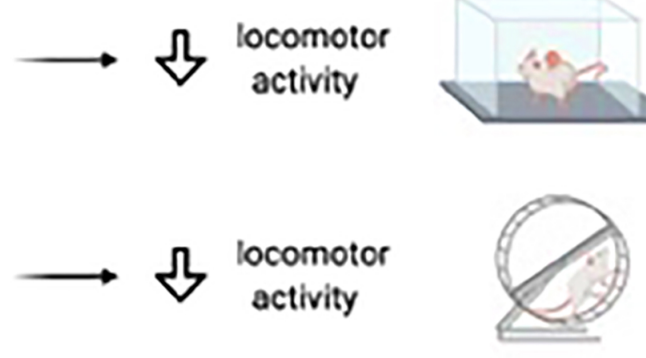

$\longrightarrow$ (Smith et al., 2012)

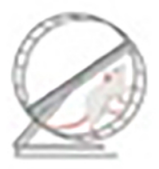

(Hosken et al., 2015)
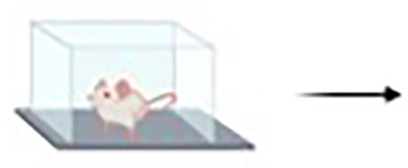

(Ma et al., 2017a)

locomotor
activity
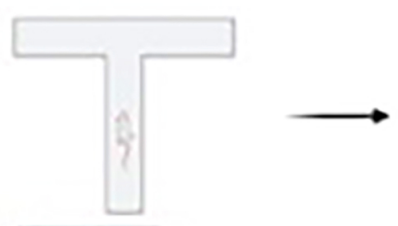

(Albert-Gascó et al., 2017)

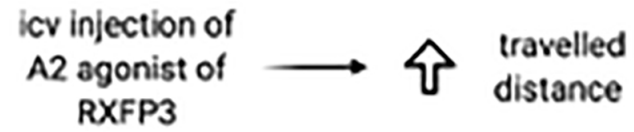

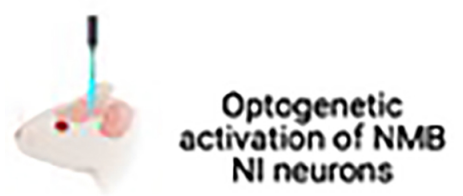

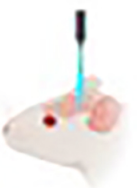

tivation of NM

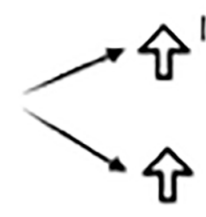

locomotor

activity

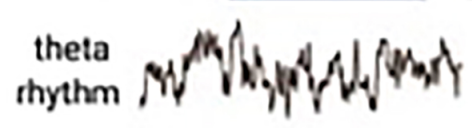

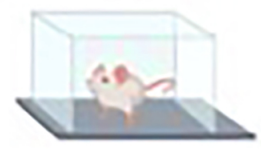

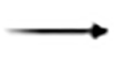

(Farooq et al., 2016)

FIGURE 2 | Summary of the main effects of NI-RLN3-RXFP3 activation on locomotor activity.

of this electrophysiological coupling between the hippocampus and the NI, asymmetric bidirectional connections between these structures were identified in the rat, with a stronger ascending NI to hippocampus projection than the opposing descending connection (Sánchez-Pérez et al., 2015). In fact, in a more recent study in mice, specific optogenetic stimulation of medial septal projections to the NI induced an increase in theta band power (Lu et al., 2020).

The involvement of the NI in hippocampal theta rhythm has been further elucidated in two transgenic mouse models (Szönyi et al., 2019; Lu et al., 2020). In one case (Szönyi et al., 2019), the investigators stimulated overall NI neurons, and in the other case, the investigators took advantage of a distinct neurochemical composition of the NI population of neurons using optogenetics (Lu et al., 2020). Szönyi and colleagues targeted the broad population of NI GABAergic neurons in vGAT-Cre mice and observed that optogenetic stimulation of the NI induced a decrease in theta power recorded in the CA1 field that was associated with effects on local somatostatin interneurons (Szönyi et al., 2019). In contrast, Lu and colleagues produced a transgenic mouse expressing Cre recombinase under the control of the NMB promotor ( $\mathrm{Lu}$ et al., 2020), as NMB is widely expressed in mouse NI neurons (Chronwall et al., 1985). Optogenetic stimulation of NI NMB neurons induced an increase in theta power recorded in the CA1 field and a concomitant increase of locomotor activity (Lu et al., 2020). The opposing effects of the NI stimulation on theta might be explained by the assessment of different neuronal targets. However, most neurons 
of the NI express glutamic acid dehydrogenase (GAD) in the rat (Olucha-Bordonau et al., 2003; Ma et al., 2007) and mouse (Szönyi et al., 2019), and a recent report confirms that all NMB neurons are vGAT-positive (i.e., GABAergic; Nasirova et al., 2020). However, the surrounding nuclei contain GABA neurons (Nasirova et al., 2020) that when stimulated, as occurs in the vGAT-Cre mouse (Szönyi et al., 2019) could produce complex interactions leading to different behaviors to those obtained from specific activation of NMB neurons (Lu et al., 2020).

\section{NUCLEUS INCERTUS/RELAXIN-3 INDUCTION OF LOCOMOTOR ACTIVITY AND AROUSAL}

In awake animals, a major component of hippocampal theta derives from locomotor activity (Vanderwolf, 1969). There is a direct non-linear relationship between the speed of movement and theta rhythm so that at higher speeds a harmonic of $16 \mathrm{~Hz}$ appears along with a series of higher frequency harmonics (Sheremet et al., 2016). There is also evidence of a relationship between locomotor activity, behavioral arousal, and NI activity (Ryan et al., 2011; Farooq et al., 2016).

In terms of interactions with other central arousal systems, NI neurons in the rat express a high density of CRF receptor 1 (CRF1; Bittencourt and Sawchenko, 2000; Van Pett et al., 2000), consistent with the proposal that CRF1 activation in the NI represents a mechanism for distributing a CRF-elicited arousal response during stressful conditions (Tanaka et al., 2005). Indeed, specific stressors have been shown to increase NI activity (Calvez et al., 2016). Furthermore, NI neurons in the rat express the orexin receptors, OX1 and OX2 (Blasiak et al., 2015), which represents another signaling mechanism for delivering arousal-related stimuli to the NI. Orexin-A application induced depolarization of NI neurons expressing relaxin-3 (Blasiak et al., 2015). Interference with orexin signaling by injection of an OX2 antagonist (but not OX1 antagonist) into the NI impaired the reinstatement of alcohol-seeking induced by the anxiogenic drug, yohimbine, in alcohol-preferring rats. Application of the same OX2 antagonist prevented NI cell depolarization induced by orexin-A in an ex vivo slice preparation (Kastman et al., 2016). Thus, the NI could mediate the effect of orexins on foodand alcohol-seeking by enhancing locomotor activity and thetarelated processes.

A relationship between the NI and the associated relaxin-3 system and arousal and locomotion was further implied by studies of relaxin-3 knockout (Rln3 KO) mice. Both male and female $\mathrm{KO}$ mice displayed a hypoactive phenotype on voluntary, home-cage running wheels during the dark phase (Smith et al., 2012), a finding in agreement with the subsequent observation that male and female Rxfp3 KO mice displayed hypoactivity in the dark phase (Hosken et al., 2015; Figure 2).

A direct relationship between arousal and locomotion was demonstrated in studies of microstimulation of the NI in conscious rats. Ipsilateral microstimulation of the NI at a high frequency increased speed, mobility, and rotations at short latencies that lasted for a short time after stimulus cessation
(Farooq et al., 2016). Sustained chemogenetic activation of the NI in rats also produced increased locomotor activity in the home cage and a novel environment, and desynchronized cortical EEG corresponding to activation of arousal mechanisms. Furthermore, during the retrieval of fear memory, chemogenetic activation of NI neurons resulted in increased head-scan and vigilance behavior (Ma et al., 2017a). In mice, increased locomotor activity was observed following the optogenetic activation of NMB NI neurons, in parallel with increased hippocampal theta rhythm (Lu et al., 2020).

Thus, several findings using different approaches, in rats and mice, point to a direct association between locomotor activity and hippocampal theta rhythm and reveal that both can be triggered by the activation of NI neurons. Notably, although anatomical studies have focused on ascending connections, a dense NMB plexus occurs in the inferior olivary nucleus (Lu et al., 2020) that could mediate the interplay between theta and arousal locomotion and cerebellar processing. Furthermore, this plexus is relaxin-3 negative (Nasirova et al., 2020), which suggests that different populations of NI neurons could play different roles in the modulation of theta rhythm activity concerning locomotion.

\section{NUCLEUS INCERTUS IN HIPPOCAMPAL-DEPENDENT DECLARATIVE MEMORY}

Declarative memory is the capacity to recall information about past facts, places, and events, and primarily depends on the integrity of the hippocampus. Given that a central role of the NI and its associated peptidergic systems is the modulation of hippocampal theta rhythm, it is logical that the NI may be involved in the acquisition and retrieval of declarative and spatial memories. The clinical features studied in the famous HM patient reported a key role of the hippocampus in declarative memory (Squire, 2004), but the strong effect of location and space on hippocampal cell activity suggests that space is of primary importance to declarative memory formation and must be considered as the central element in episodic and semantic memories (Buzsáki and Moser, 2013).

A likely direct role for the NI in spatial memory processes was demonstrated by Nategh and colleagues in studies in which they produced a transient inactivation of the NI in rats by local lidocaine injection before the performance of different aspects of the Morris water maze (MWM) test (Nategh et al., 2015). Lidocaine inactivation of the NI impaired both the acquisition and retrieval of the memory of the location of the submerged platform, but not memory consolidation, assessed in the spatial reference memory test (Nategh et al., 2015). Also, intra-NI lidocaine disrupted working memory in the MWM learning protocol (Nategh et al., 2015). These studies did not determine the site(s) at which NI inactivation produced these effects, which potentially include the hippocampus and other neural nodes within the septohippocampal system such as the supramammillary nucleus, MS, or entorhinal cortex, although the poor performance in lidocaine-treated rats during acquisition and retrieval was shown to result in decreased activation of both 
c-fos and pCREB in the pyramidal layer of the CA1 hippocampal field (Nategh et al., 2015). However, transient inactivation with lidocaine does not provide a selective assessment of the participation of the NI in these processes, as surrounding areas may be also affected. Currently, studies using chemogenetic inactivation or activation of the NI on performance in the MWM have not been reported.

However, possible involvement of NI-related, relaxin3/RXFP3 signaling has been explored. Thus, while specific Cre-dependent depletion of RXFP3 from somatostatin interneurons in the dentate gyrus of mice expressing a floxedRxfp3 did not result in impairment of performance of the MWM memory test (Haidar et al., 2017); RXFP3 depletion in the MS of these mice resulted of impairment of memory formation and retrieval in the MWM (Haidar et al., 2019; Figure 3). More specifically, AAV-Cre induced deletion of RXFP3 in the dentate gyrus of the hippocampus in floxed-Rxfp3 mice produced an impairment in an appetitive T-maze task and spatial working memory in a continuous spontaneous alternation test in a Y-maze (Haidar et al., 2017), suggesting that the relaxin-3containing inputs to somatostatin- and GABA-positive neurons in the hilar region could regulate hippocampal and cognitive processing associated with these tasks (Haidar et al., 2017). Similarly, depletion of RXFP3 in the medial septum/diagonal band of Broca (MS/DB) in the floxed-Rxfp3 mice produced impairment of the long-term reference memory in the MWM (Haidar et al., 2019). Consistent with these studies, icv infusion of the RXFP3 agonist, RXFP3-A2 resulted in impairment of spatial working memory in rats in a delayed spontaneous alternation T-maze test (Albert-Gascó et al., 2017). Additionally, RXFP3-A2 administration increased pERK immunostaining in cholinergic (ChAT-positive) neurons in the MS/DB regions (Albert-Gascó et al., 2017). Together these and other data indicate that RXFP3 signaling can regulate cognitive processing activity in the hippocampus and MS/DB via NI relaxin-3 projections.

Further support for the involvement of the NI in the regulation of memory-related hippocampal and septal circuits has been obtained in recent studies employing optogenetics and transgenic mouse lines. The study of Szönyi et al. (2019) reported that optogenetic activation of NI GABAergic neurons impaired the capacity for creating contextual associations to an unconditioned stimulus (US) via inhibition of hippocampal somatostatin interneurons. Furthermore, while a synchronized activation of NI GABAergic neurons generated an inhibition of the formation of contextual fear memories, inhibition of NI GABAergic neurons produced a stronger contextual fear memory formation; this effect could be enhanced by concurrent inhibition of excitatory MS neurons by GABAergic NI collaterals (Szönyi et al., 2019). However, this study used a GAD-Cre mouse in which NI activation-inactivation is produced after the infusion of an AAV-floxed-channelrhodopsin II (ChRII) into the NI. Thus, this manipulation may, in fact, affect other GABAergic neurons in the area. In this experimental approach, the activation could also be extended to intrinsic non-projecting GABA neurons and GABA neurons in other nuclei in the region directly or indirectly projecting to forebrain areas involved in memory processes (Wirtshafter and Stratford, 1993). In a more recent study, activation of NMB-positive, GABAergic neurons in the NI of mice increased locomotor activity, arousal, and hippocampal theta rhythm (Lu et al., 2020). Lu and colleagues observed that the NI-induced effects within the MS were quite specific, as activation of MS glutamatergic and cholinergic neurons increased locomotor speed, arousal, and theta power, whereas activation of MS GABAergic did not induce locomotion (Lu et al., 2020).

Although it appears clear there is a direct involvement of the NI in memory processes, as revealed by its impact on hippocampal theta rhythm and contextual perception and memory, there remain gaps in our knowledge related to the exact role of this intriguing signaling system. Most research so far has centered on the septum and hippocampus. However, other targets of the NI including the supramammillary nucleus, the median raphe, and the interpeduncular nuclei also provide ascending innervation to the septohippocampal system, thus modulating or actively driving, theta and memory systems. Similarly, the effect of the NI on these intermediary targets has not been explored. For example, the supramammillary nucleus may play a pivotal role, as it is directly involved in modulating the frequency of hippocampal theta rhythm (Kocsis and Vertes, 1994, 1997; McNaughton et al., 1995; Pan and McNaughton, 1997). Furthermore, the supramammillary nucleus has been reported to be involved in foraging mechanisms in response to ghrelin signaling (Le May et al., 2019) and RXFP3 is expressed in this region. Also, the supramammillary nucleus is involved in processing contextual and social novelty signals conveying it to the CA2 and dentate gyrus of the hippocampus, respectively (Chen et al., 2020), spatial memory retrieval (Li et al., 2020), and theta and gamma oscillations during REM sleep (Billwiller et al., 2020). Thus, the supramammillary nucleus, like the NI, is implicated in spatial and memory processing, and in activating food-seeking circuits. Notably, however, the NI is a heterogeneous nucleus containing different kinds of neurons. In fact, in a transgenic mouse expressing Cre recombinase under the control of the relaxin-3 promotor, a co-injection of a GFP-CreOn and a TdT-Cre-Off viral vector, it was possible to differentiate the relaxin-3 positive from the relaxin-3 negative projections, and there is some mismatch between these types of fibers in the supramammillary and the interpeduncular nuclei (Nasirova et al., 2020). Thus, further studies are needed to discriminate between the specific roles of each neuronal type in the NI in particular aspects of memory formation consolidation and/or retrieval in various experimental species.

\section{NUCLEUS INCERTUS IN AMYGDALA-DEPENDENT IMPLICIT MEMORIES}

Innervation of the medial and extended amygdala (MeA) by the $\mathrm{NI}$ in the rat is consistent with a role for this ascending system in emotional processing. The distribution of anterogradely-labeled nerve fibers following tracer injections into the NI and the presence of relaxin-3 fibers revealed a high level of labeling in the medial and extended amygdala, where they make contact 


\section{Lidocaine inactivation of the NI}
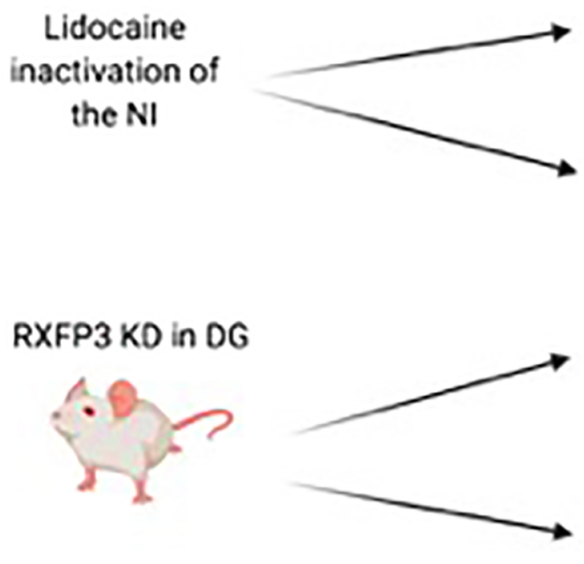

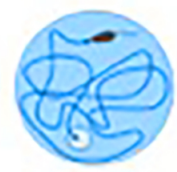

activation of c-fos and pCREB (hippocampus)

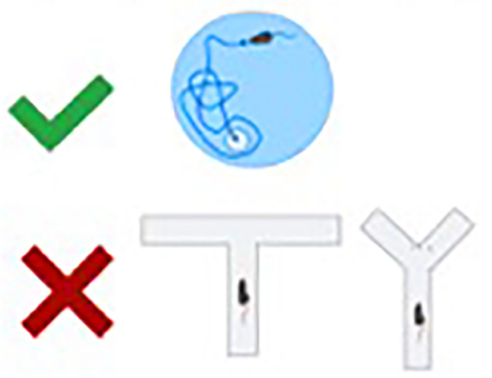

\section{RXFP3 KD in MS/DB}<smiles>C1CC2CCC(CC2)O1</smiles>
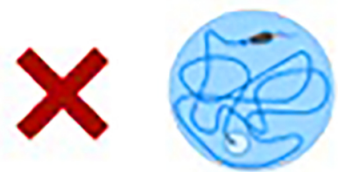

(Nategh et al., 2015)
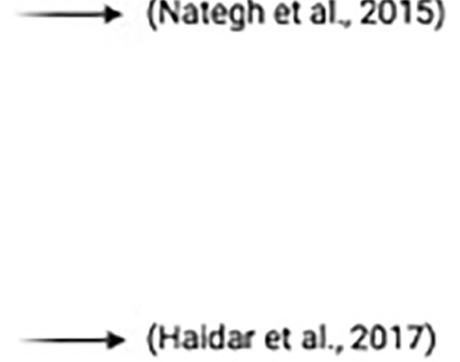

icv infusion of the RXFP3 agonist A2 (NI)
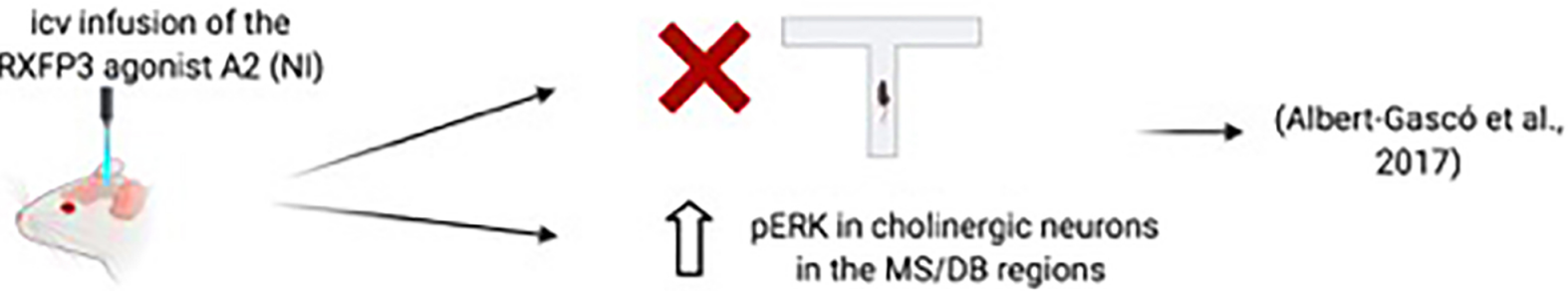

\section{T PERK in cholinergic neurons in the MS/DB regions}
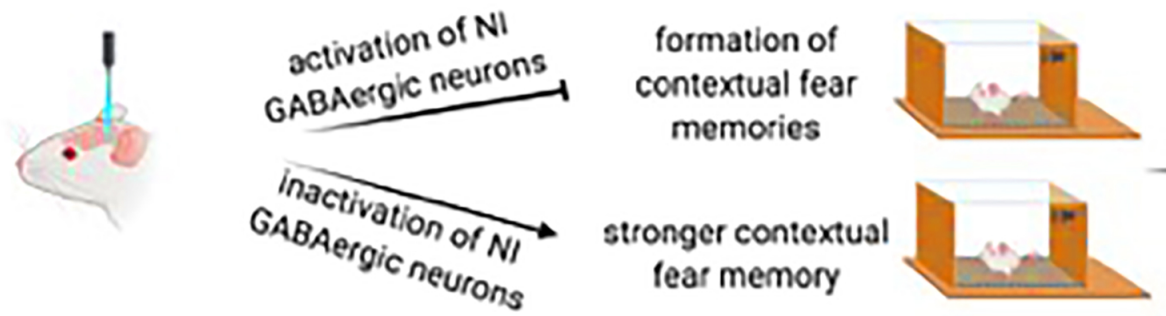

(Szónyi et al., 2019)

FIGURE 3 | Summary of data demonstrating the involvement of the NI-RLN3-RXFP3 system in declarative and contextual memory.

with calcium-binding protein-positive neurons (Santos et al., 2016). By contrast, the basolateral and cortical amygdala are essentially devoid of NI and relaxin-3 fibers (Santos et al., 2016). Notably, the central amygdala and the lateral divisions of the bed nucleus of the stria terminalis essentially lack fibers, whereas in situ hybridization studies identify a high density of RXFP3 mRNA-positive neurons in both the central amygdala and/or the lateral nuclei of the bed nucleus of the stria terminalis in rat and mouse (Ma et al., 2007; Smith et al., 2010). However, a comparison of the density and distribution of relaxin-3 fibers in rats and mice reveal that while there is a similar distribution, the density of fibers is lower in mice than in rats (Ma et al., 2007; Smith et al., 2010). Additionally, new studies in NMB-Cre (Lu et al., 2020) and relaxin-3-Cre (Nasirova et al., 2020) mice did not describe the presence of NI fibers in the amygdala area.

The occurrence of NI/relaxin-3 fibers and RXFP3 in the amygdala suggested a possible effect of this system on fear conditioning processes, which has been investigated in some initial studies. In rats in which CRF1-expressing neurons of the NI were lesioned using CRF-saporin, acquisition of a fear response to an auditory tone was not altered, but during retrieval, lesioned rats displayed longer freezing than sham rats (Lee 
et al., 2014). Similarly, electrolytic lesions of the NI did not alter fear acquisition but impaired fear extinction (Pereira et al., 2013). Furthermore, NI activation by CNO administration in rats injected previously with an AAV1/2-hM3Dq into the NI resulted in a significant reduction of freezing after the fear acquisition. However, this reduction of the fear response was accompanied by an increase in head scanning during extinction tones ( $\mathrm{Ma}$ et al., 2017a; Figure 4). Notably, concerning the latter effect, CNO may have also activated surrounding pontine centers such as the dorsal tegmental and posterodorsal tegmental nuclei, which are also implicated in the control of head movements (Wirtshafter and Stratford, 1993).

These results indicate that extinction is the main process targeted by NI-relaxin-3 projections during emotional memory formation. Extinction is context-dependent and other regions including the hippocampus and entorhinal cortex may provide additional regulation of amygdala function, under these conditions. Notably, extinction is dependent on contextual processing, which in turn, is the result of entorhinalhippocampal interconnections. The hippocampus plays a relevant role in context-dependent extinction (Lissek et al., 2013). The effect of context on extinction becomes clear in the renewal process, which consists of the recall of a cued fear memory that has already been extinguished. Extinction must be done in a different context than acquisition and recall to be effective (Bouton and Ricker, 1994). Notably, transient inactivation of the ventral hippocampus, rich in relaxin-3 fibers, during extinction impaired extinction, as reflected in next-day recall trials (Sierra-Mercado et al., 2011). There is a need to codify the context features during extinction learning, in a process in which the hippocampus plays a central role (Lissek et al., 2013). Thus, the NI projection to the hippocampus may filter relevant or irrelevant contextual features (Szönyi et al., 2019).

The medial and extended amygdala MexA are involved in the control of social behavior (Olucha-Bordonau et al., 2014), and neurons in these areas receive projections from the main

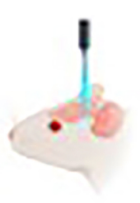

\section{CRF-saporin lesion}
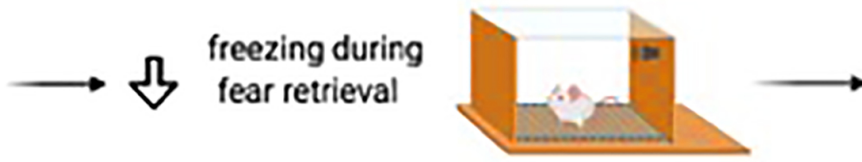

(Lee et al. 2014)

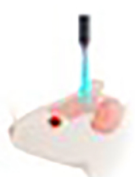
NI electrolytic lesion
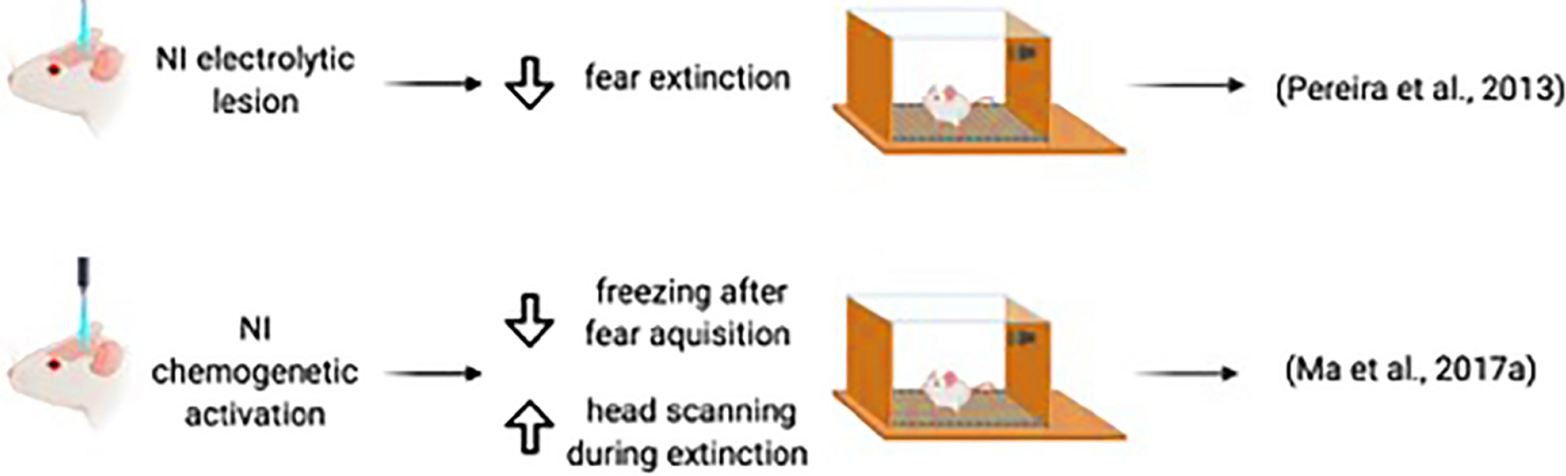

(Ma et al., 2017a)
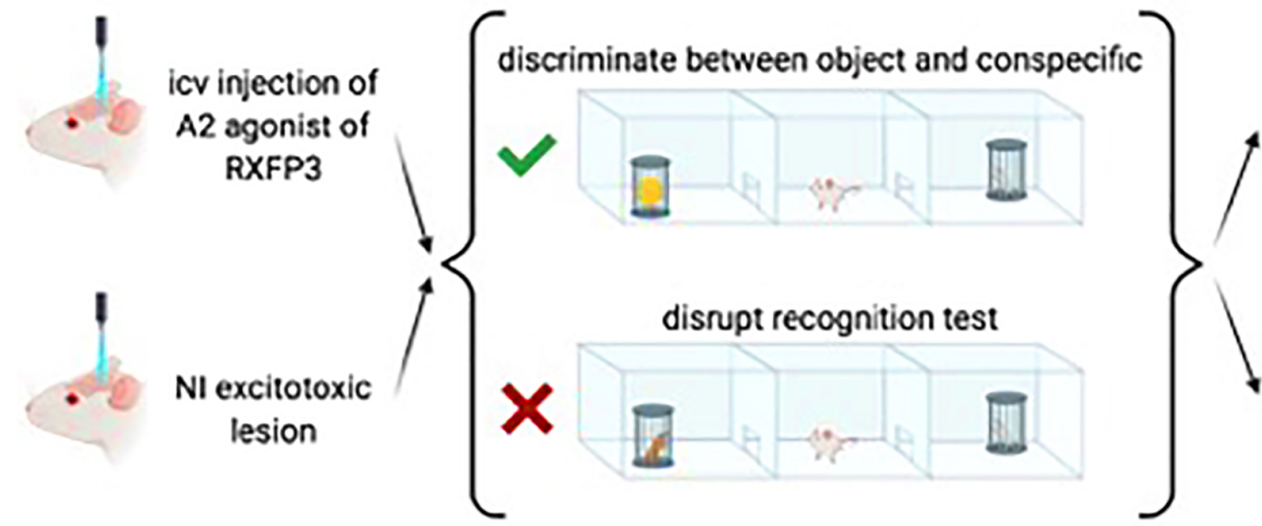
(Albert-Gascó et al..

(Garcia-Diaz et al., 2019

FIGURE 4 | Summary of the data demonstrating the involvement of the NI-RLN3-RXFP3 system in social and emotional memory. 
and accessory olfactory systems that are associated with the recognition of conspecifics (Scalia and Winans, 1975; ProSistiaga et al., 2007; Gutiérrez-Castellanos et al., 2014). Thus, the MexA is a key element in processing social recognition. In this sense, lesion of the MexA impairs social recognition (Wang et al., 2014). Also, MeA infusion of oxytocin can rescue the impaired social recognition of oxytocin knockout mice (Winslow et al., 2000). Moreover, activation of estrogen receptors in the MexA enhances social recognition (Lymer et al., 2018). Thus, the NI/relaxin-3 projections to these areas may affect social recognition.

The ability of the relaxin-3/RXFP3 system to interfere with social recognition and the possible involvement of the amygdala was assessed in the 3-chamber maze paradigm, which involved two trials (Albert-Gascó et al., 2017). In the first trial-the social test-the test rat was allowed to move between chambers containing either an inanimate object (a toy) or a conspecific. In the second trial-the recognition test-the object was replaced by a novel conspecific and the test rat could move between the familiar and the novel conspecific chambers. Normally, in the social test the rat prefers to explore the conspecific, while during the recognition test, the test rat explores the novel more than the familiar conspecific (Gheusi et al., 1994).

Intracerebroventricular infusion of an RXFP3 agonist, either before the social test or the preference test impaired the capacity to discriminate between novel and familiar conspecific, while the capacity to discriminate between the object and the conspecific subject remained intact (Albert-Gascó et al., 2017). In the same paradigm, excitotoxic lesions of the NI disrupted the recognition test, but did not alter performance in the social test (García-Díaz et al., 2019).

These data suggest a role for relaxin-3/RXFP3 signaling in the control of social recognition and discrimination and related behaviors. The data obtained are compatible with an inhibitory effect of RXFP3 activation on social recognition and indicate that a reduction in NI activity also reduces an inhibitory input to the amygdala centers involved in social recognition. However, at this stage, the specific local circuits and neurons involved in this effect have not been identified. Future research on specific interneuronal targets of NI neurons may elucidate the specific function of these cells in filtering socially relevant information. In such research the use of transgenic rodents in which a particular cell type can be switched on or off in a particular situation may provide additional information, as has been shown for the hippocampus in context conditioning (Szönyi et al., 2019), albeit with some caveats. The relative proportion of RXFP3expressing neurons in relation to other markers may provide additional cues, as seen for the expression of RXFP3 in relation to oxytocin in the MeA (Albert-Gasco et al., 2019). Notably, the medial and extended amygdala express a high density of RXFP3 (Ma et al., 2007; Smith et al., 2010). Around 60\% of medial and extended amygdala neurons co-express RXFP3 and oxytocin receptors (Albert-Gasco et al., 2019), which raises the possibility of an interaction between these signaling systems during social encounters. Recent studies have demonstrated the ability of RXFP3 activation to inhibit the activity of oxytocin neurons in the hypothalamic paraventricular nucleus (Kania et al.,
$2017,2020)$, but putative interactions of relaxin-3 and oxytocin signaling within the amygdala have not been investigated at the behavioral, neurophysiological or cell signaling level.

The restriction of relaxin-3 fibers to the extended amygdala and data obtained from pharmacological and broad lesion approaches indicate an effect on social behavior. However, these approaches lack sufficient accuracy in the present context in which different neuronal types are located in such a small pontine center. The fact that the NI projects at the same time to interrelated emotional and memory processing centers like the hippocampus, prefrontal cortex, and MexA raises the possibility of coordinated control of particular aspects of their function. For example, CRF activation of NI neurons can suppress prefrontal cortex LTP obtained from hippocampal stimulation (Farooq et al., 2013). In the future, it will be necessary to use specific biotechnology tools to determine the exact role of each signaling system in each aspect of social memory and/or interaction.

\section{CONCLUSIONS}

There is now considerable anatomical, physiological, molecular, and behavioral evidence supporting a role for the NI in processes associated with memory acquisition, consolidation, retrieval, and/or extinction. NI projections target key structures involved in explicit and implicit memory, including the hippocampus, MS, amygdala, and prefrontal cortex. Characterization of the relative contribution of each NI neuron population, including those containing one or more neuropeptides to each of these targets may shed light on the specific modulation by the NI of the function performed by each of these structures and associated circuits. For example, the NI projection to the septohippocampal system is strongly implicated as a key component of the subcortical system driving hippocampal theta rhythm. More specific and powerful methods based on viral tools containing specific peptide promotors may provide additional insights through the use of optogenetics and chemogenetics in controlled behavioral paradigms (Wykes et al., 2020).

At a neurophysiological level, there is a clear association between NI activity and hippocampal theta rhythm and synchronization between the hippocampus and the NI, but under certain conditions, increased NI activity may focally induce a decrease in hippocampal theta activity via inhibition of hippocampal somatostatin interneurons. These data might be best explained based on a role in increasing the "signal-to-noise" in memory processing. Currently, there is a lack of data in other mammalian taxa about the relative proportional occurrence of relaxin-3 neurons in the four centers containing these neurons in rodents (but see Ma et al., 2009b), and further comparative studies will be important for revealing similar or differential functions of this system in particular taxa, including humans, under both normal and pathophysiological conditions.

At a molecular level, RXFP3 activation by relaxin-3 may induce neuronal responses via two main signaling pathways, one directly through inhibition of cAMP synthesis that may reduce the level of cAMP-PKA pathway activity, and the other indirectly through altered levels of ERK phosphorylation. The balance between these two pathways and their effects on neuronal 
ion channels and firing may result in the erasing and enhancing of different aspects of memory formation.

Finally, at a behavioral level, it has become clear that the $\mathrm{NI}$ and the relaxin-3/RXFP3 system can modulate declarative memories, as reflected by effects on multiple aspects of spatial processing in the T-maze test and the MWM. Furthermore, $\mathrm{NI}$ and relaxin-3/RXFP3 signaling can also influence social recognition and the extinction of fear conditioning. Thus, specific aspects of cognitive and emotional processing can be modulated by particular components of the projections arising from the NI and its associated peptidergic systems.

\section{AUTHOR CONTRIBUTIONS}

IG-M and FO-B: conceptualization. IG-M, FR-B, AM-O, and FO-B: writing-original draft preparation. HA-G, EC-G, FR-B,

\section{REFERENCES}

Abel, T., Nguyen, P. V., Barad, M., Deuel, T. A. S., Kandel, E. R., and Bourtchouladze, R. (1997). Genetic demonstration of a role for PKA in the late phase of LTP and in hippocampus-based long-term memory. Cell 88, 615-626. doi: 10.1016/s0092-8674(00)81904-2

Albert-Gascó, H., García-Avilés, Á., Moustafa, S., Sánchez-Sarasua, S., Gundlach, A. L., Olucha-Bordonau, F. E., et al. (2017). Central relaxin-3 receptor (RXFP3) activation increases ERK phosphorylation in septal cholinergic neurons and impairs spatial working memory. Brain Struct. Funct. 222, 449-463. doi: 10.1007/s00429-016-1227-8

Albert-Gasco, H., Sanchez-Sarasua, S., Ma, S., García-Díaz, C., Gundlach, A. L., Sanchez-Perez, A. M., et al. (2019). Central relaxin-3 receptor (RXFP3) activation impairs social recognition and modulates ERK-phosphorylation in specific GABAergic amygdala neurons. Brain Struct. Funct. 224, 453-469. doi: 10.1007/s00429-018-1763-5

Alonso, A., and García-Austt, E. (1987a). Neuronal sources of theta rhythm in the entorhinal cortex of the rat. I. Laminar distribution of theta field potentials. Exp. Brain Res. 67, 493-501. doi: 10.1007/BF00247282

Alonso, A., and García-Austt, E. (1987b). Neuronal sources of theta rhythm in the entorhinal cortex of the rat. II. Phase relations between unit discharges and theta field potentials. Exp. Brain Res. 67, 502-509. doi: 10.1007/BF002 47283

Apergis-Schoute, A. M., Dębiec, J., Doyère, V., LeDoux, J. E., Schafe, G. E., Debiec, J., et al. (2005). Auditory fear conditioning and long-term potentiation in the lateral amygdala require ERK/MAP kinase signaling in the auditory thalamus: a role for presynaptic plasticity in the fear system. J. Neurosci. 25, 5730-5739. doi: 10.1523/JNEUROSCI.0096-05.2005

Banerjee, A., Shen, P.-J., Ma, S., Bathgate, R. A., and Gundlach, A. L. (2010). Swim stress excitation of nucleus incertus and rapid induction of relaxin-3 expression via CRF1 activation. Neuropharmacology 58, 145-155. doi: 10.1016/j.neuropharm.2009.06.019

Bathgate, R. A., Samuel, C. S., Burazin, T. C., Layfield, S., Claasz, A. A., Reytomas, I. G., et al. (2002). Human relaxin gene 3 (H3) and the equivalent mouse relaxin (M3) gene. Novel members of the relaxin peptide family. J. Biol. Chem. 277, 1148-1157. doi: 10.1074/jbc.M107882200

Berridge, C. W., and Waterhouse, B. D. (2003). The locus coeruleusnoradrenergic system: modulation of behavioral state and state-dependent cognitive processes. Brain Res. Brain Res. Rev. 42, 33-84. doi: 10.1016/s01650173(03)00143-7

Billwiller, F., Castillo, L., Elseedy, H., Ivanov, A. I., Scapula, J., Ghestem, A., et al. (2020). GABA-glutamate supramammillary neurons control theta and gamma oscillations in the dentate gyrus during paradoxical (REM) sleep. Brain Struct. Funct. 225, 2643-2668. doi: 10.1007/s00429-020-02146-y

Bittencourt, J. C., and Sawchenko, P. E. (2000). Do centrally administered neuropeptides access cognate receptors?: an analysis in the central
$\mathrm{AG}$, and FO-B: writing-review and editing. IG-M and AMO: figure preparation. All authors have read and agreed to the published version of the manuscript. All authors contributed to the article and approved the submitted version.

\section{FUNDING}

The research by the authors reviewed in this article was funded by Fundación Alicia Koplowitz, Spain, grant number 191436 (FO-B, FR-B, EC-G, AM-O); the Spanish Ministerio de Ciencia, Innovación y Universidades, grant number RTI2018-095698B-I00 (FO-B, FR-B, EC-G, IG-M); Generalitat Valenciana, grant number GV/2019/088 (EC-G); Universitat Jaume I, grant number UJI-B2019-54 (FO-B) and UJI-A2017-17 (FR-B); and National Health and Medical Research Council of Australia, grant number 1067522 (AG).

corticotropin-releasing factor system. J. Neurosci. 20, 1142-1156 doi: 10.1523/JNEUROSCI.20-03-01142.2000

Bland, B. H., Oddie, S. D., Colom, L. V., and Vertes, R. P. (1994). Extrinsic modulation of medial septal cell discharges by the ascending brainstem hippocampal synchronizing pathway. Hippocampus 4, 649-660. doi: 10.1002/hipo.450040604

Blasiak, A., Blasiak, T., Lewandowski, M. H., Hossain, M. A., Wade, J. D., and Gundlach, A. L. (2013). Relaxin-3 innervation of the intergeniculate leaflet of the rat thalamus-neuronal tract-tracing and in vitro electrophysiological studies. Eur. J. Neurosci. 37, 1284-1294. doi: 10.1111/ejn.12155

Blasiak, A., Siwiec, M., Grabowiecka, A., Blasiak, T., Czerw, A., Blasiak, E., et al. (2015). Excitatory orexinergic innervation of rat nucleus incertus-Implications for ascending arousal, motivation and feeding control. Neuropharmacology 99, 432-447. doi: 10.1016/j.neuropharm.2015. 08.014

Blum, S., Moore, A. N., Adams, F., and Dash, P. K. (1999). A mitogenactivated protein kinase cascade in the CA1/CA2 subfield of the dorsal hippocampus is essential for long-term spatial memory. J. Neurosci. 19, 3535-3544. doi: 10.1523/JNEUROSCI.19-09-03535.1999

Bouton, M. E., and Ricker, S. T. (1994). Renewal of extinguished responding in a second context. Anim. Learn. Behav. 22, 317-324. doi: 10.3758/BF03209840

Burazin, T. C. D., Bathgate, R. A. D., Macris, M., Layfield, S., Gundlach, A. L., and Tregear, G. W. (2002). Restricted, but abundant, expression of the novel rat gene-3 (R3) relaxin in the dorsal tegmental region of brain. J. Neurochem. 82, 1553-1557. doi: 10.1046/j.1471-4159.2002.01114.x

Burgess, N. (2006). Spatial memory: how egocentric and allocentric combine. Trends Cogn. Sci. 10, 551-557. doi: 10.1016/j.tics.2006.10.005

Burlet, S., Tyler, C. J., and Leonard, C. S. (2002). Direct and indirect excitation of laterodorsal tegmental neurons by hypocretin/orexin peptides: implications for wakefulness and narcolepsy. J. Neurosci. 22, 2862-2872. doi: 10.1523/JNEUROSCI.22-07-02862.2002

Buzsáki, G., and Moser, E. I. (2013). Memory, navigation and theta rhythm in the hippocampal-entorhinal system. Nat. Neurosci. 16, 130-138. doi: 10.1038/nn. 3304

Buzsáki, G., Leung, L. W., and Vanderwolf, C. H. (1983). Cellular bases of hippocampal EEG in the behaving rat. Brain Res. 287, 139-171. doi: 10.1016/0165-0173(83)90037-1

Calvez, J., de Ávila, C., and Timofeeva, E. (2017). Sex-specific effects of relaxin-3 on food intake and body weight gain. Br. J. Pharmacol. 174, 1049-1060. doi: 10.1111/bph.13530

Calvez, J., de Ávila, C., Matte, L.-O., Guèvremont, G., Gundlach, A. L., and Timofeeva, E. (2016). Role of relaxin-3/RXFP3 system in stressinduced binge-like eating in female rats. Neuropharmacology 102, 207-215. doi: 10.1016/j.neuropharm.2015.11.014

Cervera-Ferri, A., Guerrero-Martínez, J., Bataller-Mompeán, M., TabernerCortes, A., Martínez-Ricós, J., Ruiz-Torner, A., et al. (2011). Theta 
synchronization between the hippocampus and the nucleus incertus in urethane-anesthetized rats. Exp. Brain Res. 211, 177-192. doi: 10.1007/s00221011-2666-3

Ch'ng, S. S., Fu, J., Brown, R. M., Smith, C. M., Hossain, M. A., McDougall, S. J., et al. (2019). Characterization of the relaxin family peptide receptor 3 system in the mouse bed nucleus of the stria terminalis. J. Comp. Neurol. 527, 2615-2633. doi: 10.1002/cne.24695

Chen, G., King, J. A., Burgess, N., and O'Keefe, J. (2013). How vision and movement combine in the hippocampal place code. Proc. Natl. Acad. Sci. U S A 110, 378-383. doi: 10.1073/pnas.1215834110

Chen, S., He, L., Huang, A. J. Y., Boehringer, R., Robert, V., Wintzer, M. E., et al. (2020). A hypothalamic novelty signal modulates hippocampal memory. Nature 586, 270-274. doi: 10.1038/s41586-020-2771-1

Chronwall, B. M., Skirboll, L. R., and O’Donohue, T. L. (1985). Demonstration of a pontine-hippocampal projection containing a ranatensin-like peptide. Neurosci. Lett. 53, 109-114. doi: 10.1016/0304-3940(85)90105-3

Drieu, C., and Zugaro, M. (2019). Hippocampal sequences during exploration: mechanisms and functions. Front. Cell. Neurosci. 13:232. doi: 10.3389/fncel. 2019.00232

Evstratova, A., Chamberland, S., and Topolnik, L. (2011). Cell type-specific and activity-dependent dynamics of action potential-evoked $\mathrm{Ca}^{2+}$ signals in dendrites of hippocampal inhibitory interneurons. J. Physiol. 589, 1957-1977. doi: 10.1113/jphysiol.2010.204255

Farooq, U., Kumar, J. R., Rajkumar, R., and Dawe, G. S. (2016). Electrical microstimulation of the nucleus incertus induces forward locomotion and rotation in rats. Physiol. Behav. 160, 50-58. doi: 10.1016/j.physbeh.2016. 03.033

Farooq, U., Rajkumar, R., Sukumaran, S., Wu, Y., Tan, W. H., and Dawe, G. S. (2013). Corticotropin-releasing factor infusion into nucleus incertus suppresses medial prefrontal cortical activity and hippocampo-medial prefrontal cortical long-term potentiation. Eur. J. Neurosci. 38, 2516-2525. doi: 10.1111/ejn.12242

Ford, B., Holmes, C. J., Mainville, L., and Jones, B. E. (1995). GABAergic neurons in the rat pontomesencephalic tegmentum: codistribution with cholinergic and other tegmental neurons projecting to the posterior lateral hypothalamus. J. Comp. Neurol. 363, 177-196. doi: 10.1002/cne.903630203

Fourcaudot, E., Gambino, F., Humeau, Y., Casassus, G., Shaban, H., Poulain, B., et al. (2008). cAMP/PKA signaling and RIM1alpha mediate presynaptic LTP in the lateral amygdala. Proc. Natl. Acad. Sci. U S A 105, 15130-15135. doi: 10.1016/j.nlm.2014.05.005

Frey, U., Huang, Y. Y., and Kandel, E. R. (1993). Effects of cAMP simulate a late stage of LTP in hippocampal CA1 neurons. Science 260, 1661-1664. doi: $10.1126 /$ science. 8389057

Ganella, D. E., Callander, G. E., Ma, S., Bye, C. R., Gundlach, A. L., and Bathgate, R. A. D. (2013a). Modulation of feeding by chronic rAAV expression of a relaxin-3 peptide agonist in rat hypothalamus. Gene Ther. 20, 703-716. doi: $10.1038 /$ gt.2012.83

Ganella, D. E., Ma, S., and Gundlach, A. L. (2013b). Relaxin-3/RXFP3 signaling and neuroendocrine function-a perspective on extrinsic hypothalamic control. Front. Endocrinol. 4:128. doi: 10.3389/fendo.2013.00128

García-Díaz, C., Sánchez-Catalán, M. J., Castro-Salazar, E., García-Avilés, A., Albert-Gascó, H., Sánchez-Sarasúa de la Bárcena, S., et al. (2019). Nucleus incertus ablation disrupted conspecific recognition and modified immediate early gene expression patterns in 'social brain' circuits of rats. Behav. Brain Res. 356, 332-347. doi: 10.1016/j.bbr.2018.08.035

Gheusi, G., Bluthé, R. M., Goodall, G., and Dantzer, R. (1994). Social and individual recognition in rodents: methodological aspects and neurobiological bases. Behav. Process. 33, 59-87. doi: 10.1016/0376-6357(94) 90060-4

Goosens, K. A., Holt, W., and Maren, S. (2000). A role for amygdaloid PKA and $\mathrm{PKC}$ in the acquisition of long-term conditional fear memories in rats. Behav. Brain Res. 114, 145-152. doi: 10.1016/s0166-4328(00)00224-2

Goto, M., Swanson, L. W., and Canteras, N. S. (2001). Connections of the nucleus incertus. J. Comp. Neurol. 438, 86-122. doi: 10.1002/cne.1303

Goutagny, R., Jackson, J., and Williams, S. (2009). Self-generated theta oscillations in the hippocampus. Nat. Neurosci. 12, 1491-1493. doi: 10.1038/nn.2440

Gundlach, A. L., Smith, C. M., Ryan, P. J., Blasiak, A., Olucha-Bordonau, F. E., and Ma, S. (2013). "Relaxins," in Handbook of Biologically Active Peptides, ed A. Kastin (San Diego, CA: Academic Press), 907-916.
Gutiérrez-Castellanos, N., Pardo-Bellver, C., Martínez-García, F., and Lanuza, E. (2014). The vomeronasal cortex-afferent and efferent projections of the posteromedial cortical nucleus of the amygdala in mice. Eur. J. Neurosci. 39, 141-158. doi: 10.1111/ejn.12393

Haidar, M., Guèvremont, G., Zhang, C., Bathgate, R. A. D., Timofeeva, E., Smith, C. M., et al. (2017). Relaxin-3 inputs target hippocampal interneurons and deletion of hilar relaxin-3 receptors in "floxed-RXFP3" mice impairs spatial memory. Hippocampus 27, 529-546. doi: 10.1002/hipo.22709

Haidar, M., Tin, K., Zhang, C., Nategh, M., Covita, J., Wykes, A. D., et al. (2019). Septal GABA and glutamate neurons express RXFP3 mRNA and depletion of septal RXFP3 impaired spatial search strategy and long-term reference memory in adult mice. Front. Neuroanat. 13:30. doi: 10.3389/fnana.2019.00030

Hale, M. W., and Lowry, C. A. (2011). Functional topography of midbrain and pontine serotonergic systems: implications for synaptic regulation of serotonergic circuits. Psychopharmacology 213, 243-264. doi: 10.1007/s00213010-2089-z

Hartmann, M., Heumann, R., and Lessmann, V. (2001). Synaptic secretion of BDNF after high-frequency stimulation of glutamatergic synapses. EMBO J. 20, 5887-5897. doi: 10.1093/emboj/20.21.5887

Hosken, I. T., Sutton, S. W., Smith, C. M., and Gundlach, A. L. (2015). Relaxin3 receptor ( $\mathrm{rxfp} 3$ ) gene knockout mice display reduced running wheel activity: implications for role of relaxin-3/RXFP3 signalling in sustained arousal. Behav. Brain Res. 278, 167-175. doi: 10.1016/j.bbr.2014.09.028

Huang, Y. Y., Li, X. C., and Kandel, E. R. (1994). cAMP contributes to mossy fiber LTP by initiating both a covalently mediated early phase and macromolecular synthesis-dependent late phase. Cell 79, 69-79. doi: 10.1016/0092-8674(94)90401-4

Jaramillo, J., and Kempter, R. (2017). Phase precession: a neural code underlying episodic memory? Curr. Opin. Neurobiol. 43, 130-138. doi: 10.1016/j.conb. 2017.02.006

Jennes, L., Stumpf, W. E., and Kalivas, P. W. (1982). Neurotensin: topographical distribution in rat brain by immunohistochemistry. J. Comp. Neurol. 210, 211-224. doi: 10.1002/cne.902100302

Jones, B. E., and Webster, H. H. (1988). Neurotoxic lesions of the dorsolateral pontomesencephalic tegmentum-cholinergic cell area in the cat. I. Effects upon the cholinergic innervation of the brain. Brain Res. 451, 13-32. doi: 10.1016/0006-8993(88)90745-7

Kamondi, A., Acsády, L., Wang, X. J., and Buzsáki, G. (1998). Theta oscillations in somata and dendrites of hippocampal pyramidal cells in vivo: activitydependent phase-precession of action potentials. Hippocampus 8, 244-261. doi: 10.1002/(SICI)1098-1063(1998)8:3<244::AID-HIPO7>3.0.CO;2-J

Kania, A., Gugula, A., Grabowiecka, A., de Ávila, C., Blasiak, T., Rajfur, Z., et al. (2017). Inhibition of oxytocin and vasopressin neuron activity in rat hypothalamic paraventricular nucleus by relaxin-3-RXFP3 signalling. J. Physiol. 595, 3425-3447. doi: 10.1113/JP273787

Kania, A., Szlaga, A., Sambak, P., Gugula, A., Blasiak, E., Di Bonaventura, M. V. M., et al. (2020). RLN3/RXFP3 signaling in the PVN inhibits magnocellular neurons via $\mathrm{M}$-like current activation and contributes to binge eating behavior. J. Neurosci. 40, 5362-5375. doi: 10.1523/JNEUROSCI.2895-19.2020

Kastman, H. E., Blasiak, A., Walker, L., Siwiec, M., Krstew, E. V., Gundlach, A. L., et al. (2016). Nucleus incertus orexin-2 receptors mediate alcohol seeking in rats. Neuropharmacology 110, 82-91. doi: 10.1016/j.neuropharm.2016.07.006

Kocsis, B., and Vertes, R. P. (1994). Characterization of neurons of the supramammillary nucleus and mammillary body that discharge rhythmically with the hippocampal theta rhythm in the rat. J. Neurosci. 14, 7040-7052. doi: 10.1523/JNEUROSCI.14-11-07040.1994

Kocsis, B., and Vertes, R. P. (1997). Phase relations of rhythmic neuronal firing in the supramammillary nucleus and mammillary body to the hippocampal theta activity in urethane anesthetized rats. Hippocampus 7, 204-214. doi: 10.1002/(SICI)1098-1063(1997)7:2<204::AID-HIPO7>3.0.CO;2-M

Kubota, Y., Inagaki, S., Shiosaka, S., Cho, H. J., Tateishi, K., Hashimura, E., et al. (1983). The distribution of cholecystokinin octapeptide-like structures in the lower brain stem of the rat: an immunohistochemical analysis. Neuroscience 9 , 587-604. doi: 10.1016/0306-4522(83)90176-8

Kuei, C., Sutton, S., Bonaventure, P., Pudiak, C., Shelton, J., Zhu, J., et al. (2007). R3(BDelta23 27)R/I5 chimeric peptide, a selective antagonist for GPCR135 and GPCR142 over relaxin receptor LGR7: in vitro and in vivo characterization. J. Biol. Chem. 282, 25425-25435. doi: 10.1074/jbc.M701416200 
Kumar, J. R., Rajkumar, R., Jayakody, T., Marwari, S., Hong, J. M., Ma, S., et al. (2017). Relaxin' the brain: a case for targeting the nucleus incertus network and relaxin-3/RXFP3 system in neuropsychiatric disorders. Br. J. Pharmacol. 174, 1061-1076. doi: 10.1111/bph.13564

Le May, M. V., Hume, C., Sabatier, N., Schéle, E., Bake, T., Bergström, U., et al. (2019). Activation of the rat hypothalamic supramammillary nucleus by food anticipation, food restriction or ghrelin administration. J. Neuroendocrinol. 31:e12676. doi: 10.1111/jne.12676

Lee, L. C., Rajkumar, R., and Dawe, G. S. (2014). Selective lesioning of nucleus incertus with corticotropin releasing factor-saporin conjugate. Brain Res. 1543, 179-190. doi: 10.1016/j.brainres.2013.11.021

Lenglos, C., Mitra, A., Guèvremont, G., and Timofeeva, E. (2013). Sex differences in the effects of chronic stress and food restriction on body weight gain and brain expression of CRF and relaxin-3 in rats. Genes Brain Behav. 12, 370-387. doi: 10.1111/gbb.12028

Li, Y., Bao, H., Luo, Y., Yoan, C., Sullivan, H. A., Quintanilla, L., et al. (2020). Supramammillary nucleus synchronizes with dentate gyrus to regulate spatial memory retrieval through glutamate release. eLife 9:e53129. doi: 10.7554/eLife. 53129

Lissek, S., Glaubitz, B., Uengoer, M., and Tegenthoff, M. (2013). Hippocampal activation during extinction learning predicts occurrence of the renewal effect in extinction recall. NeuroImage 81, 131-143. doi: 10.1016/j.neuroimage.2013. 05.025

Liu, C., Chen, J., Kuei, C., Sutton, S., Nepomuceno, D., Bonaventure, P., et al. (2005). Relaxin-3/insulin-like peptide 5 chimeric peptide, a selective ligand for G protein-coupled receptor (GPCR)135 and GPCR142 over leucine-rich repeat-containing G protein-coupled receptor 7. Mol. Pharmacol. 67, 231-240. doi: 10.1124/mol.104.006700

Liu, C., Eriste, E., Sutton, S., Chen, J., Roland, B., Kuei, C., et al. (2003). Identification of relaxin-3/INSL7 as an endogenous ligand for the orphan G-protein-coupled receptor GPCR135. J. Biol. Chem. 278, 50754-50764. doi: 10.1074/jbc.M308995200

Lu, L., Ren, Y., Yu, T., Liu, Z., Wang, S., Tan, L., et al. (2020). Control of locomotor speed, arousal and hippocampal theta rhythms by the nucleus incertus. Nat. Commun. 11:262. doi: 10.1038/s41467-019-14116-y

Lymer, J. M., Sheppard, P. A. S., Kuun, T., Blackman, A., Jani, N., Mahbub, S., et al. (2018). Estrogens and their receptors in the medial amygdala rapidly facilitate social recognition in female mice. Psychoneuroendocrinology 89, 30-38. doi: 10.1016/j.psyneuen.2017.12.021

Ma, S., Allocca, G., Ong-Pålsson, E. K. E., Singleton, C. E., Hawkes, D., McDougall, S. J., et al. (2017a). Nucleus incertus promotes cortical desynchronization and behavioral arousal. Brain Struct. Funct. 222, 515-537. doi: 10.1007/s00429-016-1230-0

Ma, S., and Gundlach, A. L. (2015). Ascending control of arousal and motivation: role of nucleus incertus and its peptide neuromodulators in behavioural responses to stress. J. Neuroendocrinol. 27, 457-467. doi: 10.1111/jne.12259

Ma, S., Blasiak, A., Olucha-Bordonau, F. E., Verberne, A. J. M., and Gundlach, A. L. (2013). Heterogeneous responses of nucleus incertus neurons to corticotrophin-releasing factor and coherent activity with hippocampal theta rhythm in the rat. J. Physiol. 591, 3981-4001. doi: 10.1113/jphysiol.2013. 254300

Ma, S., Bonaventure, P., Ferraro, T., Shen, P.-J. J., Burazin, T. C., Bathgate, R. A. D., et al. (2007). Relaxin-3 in GABA projection neurons of nucleus incertus suggests widespread influence on forebrain circuits via G-protein-coupled receptor-135 in the rat. Neuroscience 144, 165-190. doi: 10.1016/j.neuroscience. 2006.08.072

Ma, S., Olucha-Bordonau, F. E., Hossain, M. A., Lin, F., Kuei, C., Liu, C., et al. (2009a). Modulation of hippocampal theta oscillations and spatial memory by relaxin-3 neurons of the nucleus incertus. Learn. Mem. 16, 730-742. doi: $10.1101 / \mathrm{lm} .1438109$

Ma, S., Sang, Q., Lanciego, J. L., and Gundlach, A. L. (2009b). Localization of relaxin-3 in brain of Macaca fascicularis: identification of a nucleus incertus in primate. J. Comp. Neurol. 517, 856-872. doi: 10.1002/cne.22197

Ma, S., Smith, C. M., Blasiak, A., and Gundlach, A. L. (2017b). Distribution, physiology and pharmacology of relaxin-3/RXFP3 systems in brain. $B r$. J. Pharmacol. 174, 1034-1048. doi: 10.1111/bph.13659

Martínez-Bellver, S., Cervera-Ferri, A., Martínez-Ricós, J., Ruiz-Torner, A., LuqueGarcía, A., Blasco-Serra, A., et al. (2015). Regular theta-firing neurons in the nucleus incertus during sustained hippocampal activation. Eur. J. Neurosci. 41, 1049-1067. doi: 10.1111/ejn.12884

Martínez-Bellver, S., Cervera-Ferri, A., Martínez-Ricós, J., Ruiz-Torner, A., LuqueGarcía, A., Blasco-Serra, A., et al. (2017). Causal relationships between neurons of the nucleus incertus and the hippocampal theta activity in the rat. J. Physiol. 595, 1775-1792. doi: 10.1113/JP272841

McNaughton, N., Logan, B., Panickar, K. S., Kirk, I. J., Pan, W. X., Brown, N. T., et al. (1995). Contribution of synapses in the medial supramammillary nucleus to the frequency of hippocampal theta rhythm in freely moving rats. Hippocampus 5, 534-545. doi: 10.1002/hipo.450050605

Moita, M. A. P., Lamprecht, R., Nader, K., and LeDoux, J. E. (2002). A-kinase anchoring proteins in amygdala are involved in auditory fear memory. Nat. Neurosci. 5, 837-838. doi: 10.1038/nn901

Moruzzi, G., and Magoun, H. W. (1949). Brain stem reticular formation and activation of the EEG. Electroencephalogr. Clin. Neurophysiol. 1, 455-473.

Nasirova, N., Quina, L. A., Morton, G., Walker, A., and Turner, E. E. (2020). Mapping cell types and efferent pathways in the ascending relaxin-3 system of the nucleus incertus. eNeuro 7:ENEURO.0272-20.2020. doi: 10.1523/ENEURO. 0272-20.2020

Nategh, M., Nikseresht, S., Khodagholi, F., and Motamedi, F. (2015). Nucleus incertus inactivation impairs spatial learning and memory in rats. Physiol. Behav. 139, 112-120. doi: 10.1016/j.physbeh.2014.11.014

Nuñez, A., Cervera-Ferri, A., Olucha-Bordonau, F. E., Ruiz-Torner, A., and Teruel, V. (2006). Nucleus incertus contribution to hippocampal theta rhythm generation. Eur. J. Neurosci. 23, 2731-2738. doi: 10.1111/j.1460-9568.2006. 04797.x

O'Keefe, J., and Dostrovsky, J. (1971). The hippocampus as a spatial map. Preliminary evidence from unit activity in the freely-moving rat. Brain Res. 34, 171-175. doi: 10.1016/0006-8993(71)90358-1

O’Keefe, J., and Recce, M. L. (1993). Phase relationship between hippocampal place units and the EEG theta rhythm. Hippocampus 3, 317-330. doi: 10.1002/hipo. 450030307

Olucha-Bordonau, F. E., Albert-Gascó, H., Ros-Bernal, F., Rytova, V., OngPålsson, E. K. E., Ma, S., et al. (2018). Modulation of forebrain function by nucleus incertus and relaxin-3/RXFP3 signalling. CNS Neurosci. Ther. 24, 694-702. doi: 10.1111/cns.12862

Olucha-Bordonau, F. E., Fortes-Marco, L., Otero-García, M., Lanuza, E., and Martínez-García, F. (2014). "The amygdala structure and function," in The Rat Nervous System, 4th Edn, ed G. Paxinos (San Diego, CA: Academic Press), 441-490.

Olucha-Bordonau, F. E., Otero-Garcia, M., Sanchez-Perez, A. M., Nunez, A., Ma, S., and Gundlach, A. L. (2012). Distribution and targets of the relaxin-3 innervation of the septal area in the rat. J. Comp. Neurol. 520, 1903-1939. doi: $10.1002 / \mathrm{cne} .23018$

Olucha-Bordonau, F. E., Teruel, V., Barcia-González, J., Ruiz-Torner, A., Valverde-Navarro, A. A., and Martínez-Soriano, F. (2003). Cytoarchitecture and efferent projections of the nucleus incertus of the rat. J. Comp. Neurol. 464, 62-97. doi: 10.1002/cne.10774

Pan, W. X., and McNaughton, N. (1997). The medial supramammillary nucleus, spatial learning and the frequency of hippocampal theta activity. Brain Res. 764, 101-108. doi: 10.1016/s0006-8993(97)00431-9

Parvizi, J., and Damasio, A. (2001). Consciousness and the brainstem. Cognition 79, 135-160. doi: 10.1016/s0010-0277(00)00127-x

Pastalkova, E., Itskov, V., Amarasingham, A., and Buzsáki, G. (2008). Internally generated cell assembly sequences in the rat hippocampus. Science 321, 1322-1327. doi: 10.1126/science. 1159775

Pereira, C. W., Santos, F. N., Sánchez-Pérez, A., Otero-García, M., Marchioro, M., $\mathrm{Ma}$, S., et al. (2013). Electrolytic lesion of the nucleus incertus retards extinction of auditory conditioned fear. Behav. Brain Res. 247, 201-210. doi: 10.1016/j.bbr. 2013.03.025

Pro-Sistiaga, P., Mohedano-Moriano, A., Ubeda-Bañon, I., Del Mar ArroyoJimenez, M., Marcos, P., Artacho-Pérula, E., et al. (2007). Convergence of olfactory and vomeronasal projections in the rat basal telencephalon. J. Comp. Neurol. 504, 346-362. doi: 10.1002/cne.21455

Royer, S., Zemelman, B. V., Losonczy, A., Kim, J., Chance, F., Magee, J. C., et al. (2012). Control of timing, rate and bursts of hippocampal place cells by dendritic and somatic inhibition. Nat. Neurosci. 15, 769-775. doi: 10.1038/ nn.3077 
Ruan, M., Young, C. K., and McNaughton, N. (2017). Bi-directional theta modulation between the septo-hippocampal system and the mammillary area in free-moving rats. Front. Neural Circuits 11:62. doi: 10.3389/fncir.2017.00062

Ryan, P. J., Büchler, E., Shabanpoor, F., Hossain, M. A., Wade, J. D., Lawrence, A. J., et al. (2013a). Central relaxin-3 receptor (RXFP3) activation decreases anxiety- and depressive-like behaviours in the rat. Behav. Brain Res. 244, 142-151. doi: 10.1016/j.bbr.2013.01.034

Ryan, P. J., Kastman, H. E., Krstew, E. V., Rosengren, K. J., Hossain, M. A., Churilov, L., et al. (2013b). Relaxin-3/RXFP3 system regulates alcohol-seeking. Proc. Natl. Acad. Sci. U S A 110, 20789-20794. doi: 10.1073/pnas.1317807110

Ryan, P. J., Krstew, E. V., Sarwar, M., Gundlach, A. L., and Lawrence, A. J. (2014). Relaxin-3 mRNA levels in nucleus incertus correlate with alcohol and sucrose intake in rats. Drug Alcohol Depend. 140, 8-16. doi: 10.1016/j.drugalcdep.2014. 04.017

Ryan, P. J., Ma, S., Olucha-Bordonau, F. E., and Gundlach, A. L. (2011). Nucleus incertus - an emerging modulatory role in arousal, stress and memory. Neurosci. Biobehav. Rev. 35, 1326-1341. doi: 10.1016/j.neubiorev.2011.02.004

Sánchez-Pérez, A. M., Arnal-Vicente, I., Santos, F. N., Pereira, C. W., El Mlili, N., Sanjuan, J., et al. (2015). Septal projections to the nucleus incertus in the rat: Bidirectional pathways for modulation of hippocampal function. J. Comp. Neurol. 523, 565-588. doi: 10.1002/cne.23687

Santos, F. N., Pereira, C. W., Sánchez-Pérez, A. M., Otero-García, M., Ma, S. K., Gundlach, A. L., et al. (2016). Comparative distribution of relaxin-3 inputs and calcium-binding protein-positive neurons in rat amygdala. Front. Neuroanat. 10:36. doi: 10.3389/fnana.2016.00036

Saper, C. B., and Fuller, P. M. (2017). Wake-sleep circuitry: an overview. Curr. Opin. Neurobiol. 44, 186-192. doi: 10.1016/j.conb.2017.03.021

Satoh, Y., Endo, S., Nakata, T., Kobayashi, Y., Yamada, K., Ikeda, T., et al. (2011). ERK2 contributes to the control of social behaviors in mice. J. Neurosci. 31, 11953-11967. doi: 10.1523/JNEUROSCI.2349-11.2011

Scalia, F., and Winans, S. S. (1975). The differential projections of the olfactory bulb and accessory olfactory bulb in mammals. J. Comp. Neurol. 161, 31-55. doi: 10.1002/cne.901610105

Schafe, G. E., Atkins, C. M., Swank, M. W., Bauer, E. P., Sweatt, J. D., and Ledoux, J. E. (2000). Activation of ERK/MAP kinase in the amygdala is required for memory consolidation of pavlovian fear conditioning. J. Neurosci. 20, 8177-8187. doi: 10.1523/JNEUROSCI.20-21-08177.2000

Selcher, J. C., Atkins, C. M., Trzaskos, J. M., Paylor, R., and Sweatt, J. D. (1999). A necessity for MAP kinase activation in mammalian spatial learning. Learn. Mem. 6, 478-490. doi: 10.1101/lm.6.5.478

Selcher, J. C., Nekrasova, T., Paylor, R., Landreth, G. E., and Sweatt, J. D. (2001). Mice lacking the ERK1 isoform of MAP kinase are unimpaired in emotional learning. Learn. Mem. 8, 11-19. doi: 10.1101/lm.37001

Sheremet, A., Burke, S. N., and Maurer, A. P. (2016). Movement enhances the nonlinearity of hippocampal theta. J. Neurosci. 36, 4218-4230. doi: 10.1523/JNEUROSCI.3564-15.2016

Sierra-Mercado, D., Padilla-Coreano, N., and Quirk, G. J. (2011). Dissociable roles of prelimbic and infralimbic cortices, ventral hippocampus and basolateral amygdala in the expression and extinction of conditioned fear. Neuropsychopharmacology 36, 529-538. doi: 10.1038/npp.2010.184

Smith, C. M., Hosken, I. T., Sutton, S. W., Lawrence, A. J., and Gundlach, A. L. (2012). Relaxin-3 null mutation mice display a circadian hypoactivity phenotype. Genes Brain Behav. 11, 94-104. doi: 10.1111/j.1601-183X.2011. 00730.x

Smith, C. M., Shen, P.-J., Banerjee, A., Bonaventure, P., Ma, S., Bathgate, R. A. D., et al. (2010). Distribution of relaxin-3 and RXFP3 within arousal, stress, affective and cognitive circuits of mouse brain. J. Comp. Neurol. 518, 4016-4045. doi: 10.1002/cne.22442

Smith, C. M., Walker, A. W., Hosken, I. T., Chua, B. E., Zhang, C., Haidar, M., et al. (2014). Relaxin-3/RXFP3 networks: an emerging target for the treatment of depression and other neuropsychiatric diseases? Front. Pharmacol. 5:46. doi: 10.3389/fphar.2014.00046

Squire, L. R. (2004). Memory systems of the brain: a brief history and current perspective. Neurobiol. Learn. Mem. 82, 171-177. doi: 10.1016/j.nlm.2004. 06.005
Steriade, M., and Glenn, L. L. (1982). Neocortical and caudate projections of intralaminar thalamic neurons and their synaptic excitation from midbrain reticular core. J. Neurophysiol. 48, 352-371. doi: 10.1152/jn.1982.48. 2.352

Szönyi, A., Sos, K. E., Nyilas, R., Schlingloff, D., Domonkos, A., Takács, V. T., et al. (2019). Brainstem nucleus incertus controls contextual memory formation. Science 364:eaaw0445. doi: 10.1126/science.aaw0445

Tanaka, M., Iijima, N., Miyamoto, Y., Fukusumi, S., Itoh, Y., Ozawa, H., et al. (2005). Neurons expressing relaxin 3/INSL 7 in the nucleus incertus respond to stress. Eur. J. Neurosci. 21, 1659-1670. doi: 10.1111/j.1460-9568.2005. 03980.x

Tsanov, M. (2015). Septo-hippocampal signal processing: breaking the code. Prog. Brain Res. 219, 103-120. doi: 10.1016/bs.pbr.2015.04.002

Van der Westhuizen, E. T., Sexton, P. M., Bathgate, R. A., and Summers, R. J. (2005). Responses of GPCR135 to human gene 3 (H3) relaxin in CHO-K1 cells determined by microphysiometry. Ann. N. Y. Acad. Sci. 1041, 332-337. doi: 10.1196/annals.1282.053

Van der Westhuizen, E. T., Werry, T. D., Sexton, P. M., and Summers, R. J. (2007). The relaxin family peptide receptor 3 activates extracellular signal-regulated kinase $1 / 2$ through a protein kinase C-dependent mechanism. Mol. Pharmacol. 71, 1618-1629. doi: 10.1124/mol.106.032763

Van Pett, K., Viau, V., Bittencourt, J. C., Chan, R. K., Li, H. Y., Arias, C., et al. (2000). Distribution of mRNAs encoding CRF receptors in brain and pituitary of rat and mouse. J. Comp. Neurol. 428, 191-212. doi: 10.1002/10969861(20001211)428:2<191::aid-cne1>3.0.co;2-u

Vanderwolf, C. H. (1969). Hippocampal electrical activity and voluntary movement in the rat. Electroencephalogr. Clin. Neurophysiol. 26, 407-418. doi: 10.1016/0013-4694(69)90092-3

Vertes, R. P., and Kocsis, B. (1997). Brainstem-diencephalo-septohippocampal systems controlling the theta rhythm of the hippocampus. Neuroscience 81 , 893-926. doi: 10.1016/s0306-4522(97)00239-x

Vertes, R. P., Fortin, W. J., and Crane, A. M. (1999). Projections of the median raphe nucleus in the rat. J. Comp. Neurol. 407, 555-582.

Wang, Y., Zhao, S., Liu, X., and Fu, Q. (2014). Effects of the medial or basolateral amygdala upon social anxiety and social recognition in mice. Turk. J. Med. Sci. 44, 353-359. doi: 10.3906/sag-1301-2

Wilkinson, T. N., and Bathgate, R. A. D. (2007). The evolution of the relaxin peptide family and their receptors. Adv. Exp. Med. Biol. 612, 1-13. doi: 10.1007/978-0-387-74672-2_1

Winslow, J. T., Ferguson, J. N., Young, L. J., Hearn, E. F., Matzuk, M. M., Insel, T. R., et al. (2000). Social amnesia in mice lacking the oxytocin gene. Nat. Genet. 25, 284-288. doi: 10.1038/77040

Wirtshafter, D., and Stratford, T. R. (1993). Evidence for GABAergic projections from the tegmental nuclei of gudden to the mammillary body in the rat. Brain Res. 630, 188-194. doi: 10.1016/0006-8993(93)90656-8

Wykes, A. D., Ma, S., Bathgate, R. A. D., and Gundlach, A. L. (2020). Targeted viral vector transduction of relaxin-3 neurons in the rat nucleus incertus using a novel cell-type specific promoter. IBRO Rep. 8, 1-10. doi: 10.1016/j.ibror.2019.11.006

Xu, Y.-L., Reinscheid, R. K., Huitron-Resendiz, S., Clark, S. D., Wang, Z., Lin, S. H., et al. (2004). Neuropeptide S: a neuropeptide promoting arousal and anxiolytic-like effects. Neuron 43, 487-497. doi: 10.1016/j.neuron.2004.08.005

Conflict of Interest: The authors declare that the research was conducted in the absence of any commercial or financial relationships that could be construed as a potential conflict of interest.

Copyright (C) 2021 Gil-Miravet, Mañas-Ojeda, Ros-Bernal, Castillo-Gómez, AlbertGascó, Gundlach and Olucha-Bordonau. This is an open-access article distributed under the terms of the Creative Commons Attribution License (CC BY). The use, distribution or reproduction in other forums is permitted, provided the original author(s) and the copyright owner(s) are credited and that the original publication in this journal is cited, in accordance with accepted academic practice. No use, distribution or reproduction is permitted which does not comply with these terms. 